\title{
La «Epístola prohemial» a la traducción de Los Triumphos de Apiano (1522): entre el panegírico a Rodrigo de Mendoza, marqués del Cenete, y la crónica de la guerra de las Germanías
}

\author{
A «Prohemial Letter» in Apiano's Triumphos translation (1522): \\ Between the Panegyric to Rodrigo de Mendoza, Marquis of Cenete, \\ and the Chronicle of «Germanías» War \\ Teresa Cuesta Esteve \\ (IES Molí del Sol, Mislata)
}

\begin{abstract}
RESUMEN
En la «Epístola prohemial» a su traducción de Los Triumphos (1522) de Apiano Alejandrino, Juan de Molina realiza una extensa loa dedicada a Rodrigo de Mendoza, marqués del Cenete. Dicho elogio es, a la vez que panegírico y biografía parcial, una breve crónica — la primera conocida - de la revuelta o guerra civil de las Germanías, que el marqués contribuyó a aplacar. El artículo repasa la importancia de Apiano como historiador, la divulgación y traducciones de su Historia romana, la labor de Molina como traductor y su crítica a los libros de caballerías por mendaces. Se estudia finalmente el contenido detallado de la «Epístola prohemial», teniendo en cuenta su importancia como crónica y su valor como tributo y marca ideológica.
\end{abstract}

\section{Palabras clave}

Apiano Alejandrino, Juan de Molina, Los Triumphos, traducciones humanistas, humanismo valenciano, Pier Candido Decembrio.

\begin{abstract}
In his translation of Apiano's Los Triumphos, Juan de Molina makes a panegyric to Rodrigo de Mendoza, marquis of Cenete: its «Prohemial Letter». This encomium is not only a partial biography, but also an historical explanation of the Germanías revolts. We study Apiano's paper as historian, his work's translations, Molina's task as a translator and his criticism to chivalry books. And we finally study the «Prohemial Letter», taking into account the relevance of the text as a chronical one and its symbolic values, as well.
\end{abstract}

\section{KEYWORDS}

Appianus of Alexandria, Juan de Molina, Los Triumphos, Humanist translations, Valencian Humanism, Pier Candido Decembrio. 
Recibido: 01/09/2021

Aceptado: 30/10/2021

\section{La Historia Romana de Apiano: traducciones y divulgación}

Apiano de Alejandría (s. I-II d.C.) fue uno de los mayores historiadores del imperio romano en lengua griega ${ }^{1}$. Su Historia Romana, aunque debió de alcanzar unas dimensiones considerables, solamente nos ha llegado conservada de forma parcial. Estaba compuesta por veinticuatro libros y abarcaba desde los comienzos de la historia de Roma hasta el año 35 a.C., ya que se proponía recoger todo el proceso geo-histórico de conquista romana de la cuenca mediterránea. Pero de estos libros han pervivido el sexto y séptimo completos, la primera parte del octavo, la segunda del noveno, la primera del undécimo, el duodécimo y, en un conjunto compacto, los cinco libros dedicados a las guerras civiles (libros XIII-XVII) ${ }^{2}$.

Aunque no fuera romano de origen, Apiano muestra una gran admiración por la grandeza del Imperio romano, elogiando sin cesar sus hazañas bélicas y comparándolo con otros imperios, como el persa. Precisamente el hecho de que Apiano fuera de origen alejandrino influye en el pensamiento que traslada a su obra, con la inclusión de referentes griegos como Atenas, Esparta y Tebas y la remisión genérica a «los griegos» como su principal fuente de información ${ }^{3}$. Pese a esto, presta mucha mayor importancia al Imperio romano, centro neurálgico de toda su Historia, y la acción se contempla casi exclusivamente desde la óptica romana, a través de la cual se filtran los éxitos y los fracasos bélicos.

El interés que despierta Apiano no es el de un mero compilador, aunque no deja de ser relevante el hecho de que tuviera acceso, gracias al desempeño de una función pública — fue advocatus y llegó a ser designado procuratus Augusti en Roma-, a una gran cantidad de información. Apiano se revela como la única fuente que poseemos para determinados episodios de la historia romana, sobre todo en el caso de las guerras de la Península Ibérica (las celtíbero-lusitanas y la toma de

1. Así lo destaca Gabba (1959:361), uno de los principales editores de su obra, y así se confirma en las más destacadas historias de la literatura y en los balances historiográficos generales sobre el periodo. Podemos seguir, para el análisis de la biografía y obra de Apiano, los trabajos de Pflaum (1950: 240 y ss.), así como los de reputados helenistas españoles, en especial Bravo (1975, 1977), Sancho (1980), González Rolán et alii (2000), Pérez Vilatela (2000) y Gómez Espelosín (2009, 2016), entre otros.

2. El primer libro recoge la historia de los primeros reyes de Roma; el segundo, la historia de los pueblos itálicos salvo la de los samnitas cuyas guerras contra Roma ocupan el tercero de los libros; el cuarto, las guerras con los galos; el quinto es la historia de las islas como Sicilia; el sexto es sobre la Península Ibérica; el séptimo, la historia de Aníbal; el octavo abarca las guerras contra cartagineses y númidas; el noveno, las que los romanos libraron contra ilirios y macedonios; el décimo las que se produjeron en Grecia y Asia Menor; el undécimo comprende los enfrentamientos con Siria y los partos; el duodécimo, las guerras contra el rey Mitrídates VI del Ponto; del décimo tercero al décimo séptimo tratan sobre las guerras civiles de Roma; del decimoséptimo al vigésimo primero las acaecidas en Egipto; el vigésimo segundo, se refiere a la historia de los emperadores hasta Trajano; el vigésimo tercero a la Dacia y, por último, el vigésimo cuarto a Arabia.

3. La importancia de que sea de Alejandría recae en que tiene una distinta sensibilidad ante la realidad romana, es un «cosmopolita en una megalópolis emplazada en un país ensimismado en su propia idiosincrasia egipcia» (Pérez Vilatela, 2000: 64). Considera Gómez Espelosín que «se sentía particularmente orgulloso de su lugar de origen al que consideraba legítimamente su patria, tal como afirma en el Prólogo de su historia» (2009: 246). Y ello justifica la importancia que le concede en su obra a la historia de su país de origen, Egipto, hasta el punto de ser el lugar de culminación de las guerras civiles romanas, otorgando a su ciudad natal, Alejandría, un gran papel. Véase Bucher (2000) y Luce (1964). 
Numancia), teniendo en cuenta que se han perdido las historias de Polibio y Posidonio sobre estos acontecimientos (Gómez Espelosín, 2016: 43; Sancho, 1980: 23).

La obra de Apiano, que recoge los acontecimientos históricos desde los orígenes de Roma hasta el año 35 a.C., se divide en dos partes: las guerras de Roma contra otras naciones y las que se dieron entre los propios romanos, es decir, las Guerras civiles. En este sentido, es importante destacar, a la hora de interrogarnos sobre la popularidad y el interés por apoyar las traducciones de sus obras entre los siglos XV y, sobre todo, XVI, que la escritura de las Guerras civiles se presenta con una clara intención moralizadora, en tanto que se describen como enfrentamientos dañinos, a los que dará fin el feliz surgimiento de la monarquía. La identificación que establece Apiano entre Guerras civiles y República tiene, así, como corolario que la monarquía es la mejor de las soluciones posibles (Botella, 2000: 187) .

La valoración de Apiano como historiador ha experimentado muchos cambios en el tiempo, pero fue sin duda uno de los historiadores antiguos a quienes más atención prestaron los humanistas de los siglos XV y XVI (Coroleu, 2004: 284). Hacia el año 1452 Pier Candido Decembrio tradujo su obra al latín para el Papa Nicolás V. Y esta sería la traducción utilizada a partir de 1477 para las nuevas traducciones, esta vez a diferentes lenguas vulgares - además de en castellano, al italiano, francés e inglés-, aun después de haber sido publicada la editio princeps griega por el intelectual humanista e impresor Charles Estienne el año 1551, en Basilea (Bravo, 1975: 32; Coroleu, 2004: 284) ${ }^{5}$. Posteriormente, su fama sería variada y plural ${ }^{6}$.

En la Península, los textos de Apiano gozaron de una gran importancia a partir del Renacimiento. Conocemos tres traducciones al castellano editadas en el siglo XVI: la de Juan de Molina (Valencia, 1522), en la que nos hemos de centrar; la de Diego de Salazar (Alcalá de Henares, 1536) y la de Jaume Bartomeu (Barcelona, 1592), como más adelante detallamos. En el mismo siglo XVI y a las puertas del XVII, Ambrosio de Morales en su Crónica de España (1574) y Juan de Mariana en su monumental Historia de España (1601), tomaron a Apiano como fuente principal de información sobre Numancia, aunque discreparan a la hora de narrar los hechos relacionados

4. Las fuentes que utiliza Apiano son abundantes y variadas. Autores como Jerónimo de Cardia, Julio César, Polibio, Tito Livio o Terencio Varrón son mencionados por el propio Apiano. Gómez Espelosín añade ecos de otros autores, como Plutarco, Diodoro, Posidonio y Salustio. Como comenta Gómez Espelosín: «no se limitaba a repetir de forma más o menos coherente sus fuentes de información, sino que ha procedido a seleccionar conscientemente aquellos detalles que le resultaban significativos de todo el episodio desde su propia perspectiva, que no coincide evidentemente con la de Livio» (2009: 237).

5. Apia d'alexandria, Appiano Alessandrino delle guerre civili de Romani (trad. d'Alessandro Braccio), Florencia, Heredi di Piero di Giunta, 1519; Apià d'Alexandria, Des guerres des Romains (trad. de Claude de Seyssel), Lion, Antoine Constantin, 1544 (aunque traducida ya en 1515); y An Ancient Historie and exquisite Chronicle of the Romans warres, both Civile and Foren, Londres, Raufe Newbeny and Henrie Bynniman, 1578 (Bravo, 1975: 32-36; Coroleu, 2004: 284). Sancho (1980: 35) indica que la primera edición del texto griego de Apiano se realizó el 1551 por Carlos Estéfano, quien en París publicó una Editio Appiani que comprendía el Prólogo, el Epítome del libro de la Galia, el libro Sobre África, un fragmento del libro Sobre Iliria, el libro Sobre Siria, el libro Sobre Mitrídates y los cinco libros de las Guerras Civiles. Añade que en 1557 Enrique Estéfano publicó los libros omitidos, el libro Sobre Iberia y La guerra de Aníbal junto con algunos fragmentos y el resto los tomó de la edición del 1551. Hace referencia a tres ediciones más: otra edición de Enrique Estéfano en 1592, la Editio Appiani Illycorum de David Hoeschelio en 1599 y la Editio Appiani de Alejandro Tolio de 1670, que nada añade respecto a las anteriores. Gómez Espelosín (2016: 11) señala que el año 1592 Henri Estinne llevó a cabo la primera edición de todo el texto superviviente hasta ese momento.

6. Como señala Gómez Espelosín: «Pudo haber sido utilizado por Shakespeare como fuente de información privilegiada para su Julio César [...] y al menos los cinco libros sobre las guerras civiles despertaron el interés de personajes como Marx y Engels, que mostraron en su mutua correspondencia la pasión que suscitaba su lectura» (2016: 11). En el siglo XIx pasó, en cambio, a ser juzgado como un mero compilador, que no podía compararse con historiadores como Tucídides o Polibio (Gómez Espelosín, 2016: 11-12). En la actualidad, sin embargo, nos encontramos en un nuevo periodo de revitalización de los estudios sobre el historiador. 
con el suicidio de los numantinos ${ }^{7}$. Y también Miguel de Cervantes, en su drama histórico $\mathrm{Nu}$ mancia, usa el relato de Apiano - junto con el de Morales - como base para relatar el sitio de la ciudad (De Armas, 1998: 8-10).

La obra de Apiano fue a menudo recomendada como manual de instrucción política por su valor histórico, como deja bien patente la edición de Barcelona de 1592, que fue dedicada a Felipe II, y sobre todo este comentario del censor: «obra que puede servir y ser provechosa para el buen gobierno de los reynos, provincias, repúblicas y ciudades en tiempo de paz y de guerra» (Coroleu, 2004: 286) . $^{8}$ Los traductores al castellano de Apiano, en efecto, efectuaban constantes parangones entre la confusión política romana descrita por Apiano y la situación de la contemporaneidad de España (Coroleu, 2004: 287). Y concretamente ocurre así en el texto de Alonso de Maldonado, quien, en su versión perdida de la Historia romana — que pudo haber sido redactada alrededor de 1465-, prologó su texto como Hechos de Alonso de Monroy, maestre de Alcántara, a quien dedicaría la traducción ${ }^{9}$. En el Prólogo, se establece un paralelismo moralizante entre la crisis romana y la inestabilidad social del reinado de los Trastámara (Coroleu, 2004: 287). Y del mismo modo, la edición valenciana de 1522, que Juan de Molina dedica a Rodrigo de Mendoza, comienza con una «Epístola» a modo de proemio, una carta de dedicatoria, en la que el traductor elogia el papel llevado a cabo por los dos Mendoza, Rodrigo y su hermano Diego, en la represión del levantamiento de las Germanías.

Además, algunos humanistas vieron en la obra de Apiano mucho más que un texto que transmitía valores históricos y políticos, y la ensalzaron por sus méritos literarios ${ }^{10}$. Por este motivo postula Coroleu que la obra de Apiano pudo haber sido considerada lectura de ocio, sin que esto significara negar su primordial valor instructivo y utilitario ${ }^{11}$. De hecho, en el Renacimiento aparecerá la obra de Apiano en muchos inventarios de bibliotecas privadas, dado que gozó de una gran popularidad entre las clases gobernantes (Coroleu, 2004: 290).

La versión de Juan de Molina, Los Triumphos de Apiano (Valencia, Joan Jofre, 1522) es la primera de las que conservamos editadas en España ${ }^{12}$. Sin embargo, tenemos la mención citada de

\footnotetext{
7. Mientras Apiano describe que solo un grupo de numantinos se suicidaron, Morales y Mariana indican que todos los habitantes, después de prender fuego a sus posesiones, decidieron suicidarse.

8. Esta dimensión política, que ya estaba en la traducción de Molina, también la destacan Claude de Seyssel, en el prólogo de su obra dirigida a Luís XII de Francia, y Diego de Salazar, en su edición de 1536, al subrayar su función de advertencia ante los peligros de las guerras civiles. Este último considera a Apiano el autor que con más detalle había descrito los conflictos de los romanos: «porque yo no las he hallado escriptas tan por extenso en ningun otro libro» (Coroleu, 2004: 286). Véase, para el contexto de las traducciones medievales en la Península, Alvar (2010).

9. Este texto será comentado más adelante, a propósito de la «Epístola proemial» de Molina.

10. Por ejemplo, en la edición de 1592, Enric de Cardona la describe como una obra curiosa y apacible, mientras que el censor Pere Gil indica que es curiosa y deleitable.
}

11. Justifica Coroleu (2004) que todas las versiones en lengua vulgar estén divididas en capítulos relativamente breves, a partir de la utilización de la obra como lectura de entretenimiento, puesto que la compartimentación sirve para facilitar la lectura, interrumpir cada poco y evitar el cansancio a los lectores.

12. Excede de los límites de este artículo poder demostrar que Molina traduce a Apiano al castellano muy correcta y fielmente, sin apenas modificaciones. En cuanto a ejemplares de la edición valenciana, Bravo (1975) solamente indicó los dos ejemplares que se encuentran en la Biblioteca Nacional sobre la obra de Juan de Molina y no se hizo eco del ejemplar que forma parte del fondo de la Biblioteca de la Universitat de València. Del primero de ellos (R-12620) comenta que suele ser citado de diversas maneras, siendo la más frecuente: Appiano Alexandrino, sophista. Sobre las cosas y los Triunphos de los Romanos. Así pues, en la hoja siguiente, en la «Epístola proemial» se habla de «Los triumphos de Appiano Alexandrino a España nueuamente venidos» y, al principio del libro primero se dice: «Comiença el libro primero de Appiano Alexandrino sophista: escrito sobre las cosas y triumphos delos Romanos: cuyo titulo es el triumpho Africano». Nosotros hemos optado por referirnos a ella como Los Triumphos de Apiano porque es el título que 
Alonso de Maldonado, asegurando que ha traducido los cinco libros de las guerras civiles (de los que no nos ha llegado nada más que esa alusión), y a ellos antepone el prólogo de los Hechos de Alonso de Monroy (que sí conservamos, en varios manuscritos) ${ }^{13}$. La biografía del maestre de Alcántara que compone Maldonado en estos Hechos es más extensa incluso que la de Rodrigo de Mendoza en la «Epístola prohemial» que antepone Molina a su traducción de Los Triumphos de Apiano ${ }^{14}$.

Hay en el mismo siglo, como hemos adelantado, otras dos ediciones posteriores a la de Molina: la Historia de todas las guerras civiles que hubo entre los romanos (Alcalá, Miguel de Eguía 1536), traducción realizada por Diego de Salazar también sobre el texto del humanista italiano ${ }^{15}$. Y la de Jaume Bartomeu, canónigo de Urgell (Barcelona, Sebastián de Cormellas, 1592) ${ }^{16}$, que sin embargo se ha demostrado que es un mero plagio de la edición de Alcalá de 1536 (Gil, 2003: 54) ${ }^{17}$. Casi tres siglos más tarde, contaríamos con la traducción de Miguel Cortés, chantre de la catedral de Valencia, publicada en $1852^{18}$. Y, finalmente, ya en pleno siglo XX, con la traducción de Sancho (1980), en la prestigiosa colección de «Biblioteca Clásica» de la editorial Gredos.

aparece en el primero de los folios de la obra, señalado con letras rojas (véase Figura 3). Sobre el segundo de los ejemplares que se conservan en la Biblioteca Nacional de la edición de 1522 (R-5608), podemos anotar que no tiene portada (aunque hay señales de su desaparición), tiene una encuadernación en piel y aparece el sello dorado de la Biblioteca del duque de Osuna, indicando que perteneció a la «librería de los Padres Clérigos Regulares de S. Cayetano de Madrid». La diferencia entre estas dos obras se encuentra en el colofón: mientras que en la primera se indica «a solicito maestro Juan Joffre imprimidor en su officina dicha comunmente al moli de la Rouela», el otro ejemplar escribe «dicha comunmente al moli de la Rouella». Esta pequeña diferencia en la consonante lateral (Rovela / Rovella) hace pensar a Bravo (1975) que responden a ejemplares de dos tiradas diferentes. La lectura castellana más correcta sería la de «molino de La Rovella» (Norton, 1966: 85; Bravo, 1975:33).

13. Puede consultarse la biografía en la edición de Romero (1978).

14. Véase, a propósito de la biografía de Monroy, en su contexto genérico, Beltrán (1997).

15. Historia de todas las guerras ciuiles que uno entre los romanos según que lo escriuió el muy eloquente historiador Appiano, Alexandrino. agora nuevamente traduzida de latin en nuestro vulgar castellano: Dirigida a el muy ilustre y manifico señor Juan de Tovar Marques de Berlanga, realizada por Diego de Salazar en Alcalá el año 1536. Aunque la versión de Salazar podría no ser una traducción de la versión latina, sino de una italiana, como señalan dos indicios: el primero, que el prólogo recoja de forma parcial una versión toscana de las Guerras Civiles (concretamente la presencia de parte del prólogo dedicado a don Juan de Tovar, marqués de Berlanga); el segundo, que el propio prólogo de Apiano, traducido al toscano y versionado por el humanista Alessandro Braccesi no aparece de Salazar (Botella, 2000: 189). Vincula Botella la versión de Diego de Salazar con la de Braccesi; sin embargo, se mantiene la esencia de la versión original, pero no el contenido moral del humanismo propuesto por el segundo (más defensor de la res publica al modo de los estados italianos que de la monarquía). Dicho de otro modo, si tanto en la obra original como en la Salazar se ensalza la monarquía como la mejor forma de gobierno posible, Braccesi aboga por el humanismo cívico entendido como la necesaria participación activa del individuo en la sociedad, con lo que puede alcanzar una vida más plena (vivere civile).

16. Historia de las guerras civiles de los romanos de Apiano Alexandrino historiador eloquentissimo, Y traduzida de Latin en lengua Castellana, por el Doctor Jayme Bartholomeu Canonigo de la Cathedral Iglesia de Urgel. Impresso en la muy insigne y leal Ciudad de Barcelona, en casa de Sebastian de Cormellas. Año 1592.

17. Discrepa Moll (1992) en esta relación de obras, ya que considera que la versión impresa en Alcalá en 1536, realizada por Diego de Salazar, procedería — como hemos visto en la nota anterior — de la traducción al italiano de la latina de Decembrio, traducción llevada a cabo por Alessandro Braccio (Roma, 1502). Asimismo, postula que la traducción de Jaume Bartomeu, impresa en Barcelona en 1592, sería llevada a cabo manejando la de Salazar, pero también la italiana de Braccio.

18. Cortés afirma que su traducción es la única que en España se ha realizado de la obra griega de Apiano, aunque, verdaderamente remite a otra obra, la de Johann Schweigewser, como él mismo indica en el título: Las Guerras ibéricas de Appiano Alejandrino traducidas del texto greco-latino de Juan Schweigewser al castellano con notas historicas y geograficas por D. Miguel Cortes y López, dignidad de chantre de la Santa Iglesia metropolitana de Valencia, individuo de la real Academia de Historia, y socio de Mérito de la de amigos del país de esta ciudad, Valencia, Imprenta José de Orga, impresor de la cámara de S.M., 1852. 
Apiano fue un autor que gozó sin duda de una gran popularidad entre las clases gobernantes, como testimonia la lista de libros que pertenecieron a Diego Díaz de Mendoza, el hermano de Rodrigo de Mendoza, a quien fue dedicada la traducción de Juan de Molina ${ }^{19}$. Probablemente sus textos llegaron a ser, en su género, un relativo best seller en la España del Renacimiento (Coroleu, 2004: 290). Éxito editorial que se puede justificar por la utilidad que la teoría renacentista, la teorizada por Pinciano, otorgaba a la historia. Para muchos lectores, Apiano proporcionaba información cumplida del pasado histórico de Roma, pero también ofrecía modelos ejemplares de comportamiento, es decir, otorgaba a la lectura de la historia una visión actualizadora y moralizante, totalmente esencial para mirarse en el pasado como en un espejo (Coroleu, 2004: 284-285).

\section{Apiano traducido por Pier Candido Decembrio}

El desconocimiento del griego mueve a muchos autores - herederos espirituales de Boccaccio y Petrarca, como los humanistas Pier Candido Decembrio, Poggio Bracciolini, Giannozzo Manetti, Michelle Pannonio, Coluccio Salutati, Lorenzo Valla, Leonardo Bruni, etc. - a traducir durante el siglo Xv a autoridades clásicas como Aristóteles, Tucídides, Jenofonte, Diodoro, Plutarco, Apiano o Polibio. Estos traductores eran considerados como «iniciados» capaces de hacer que el público pudiera acceder a la lectura del griego. Ante un público cuyo gusto demandaba cada vez más y mejor conocimiento directo de la tradición clásica, veían su labor como un tesoro que «donaban a la latinidad» (latine donare). A esta consciencia de su misión cultural se unía la labor política e ideológica, porque, como dice Steiner, la apertura a los clásicos «podía asegurar que el hombre moderno no se viera despojado de la sabiduría y herencia del pasado» (1980: 275-276) ${ }^{20}$.

En el caso que nos ocupa, la Historia romana de Apiano fue traducida al latín por Pier Candido Decembrio, uno de los mayores humanistas del Quattrocento europeo, entre 1452 y 1454, por encargo del Papa Nicolás V ${ }^{21}$. Esta versión fue la usada por todos los traductores de Apiano en lengua vulgar y la que estuvo disponible en las impresiones venecianas a partir de 1477 (Fig. 1) ${ }^{22}$.

19. Se puede comprobar en el libro reciente de Ferrer del Río (2020), dedicado a Rodrigo de Mendoza, que concentra, compila y actualiza algunas de sus importantes aportaciones anteriores.

20. La nueva actitud de los traductores viene de la mano de una profesionalización de la traducción. Como señala Morales: «el desconocimiento general del griego requiere de unas generaciones de humanistas que se afanan en su estudio en torno a los maestros helenos emigrados a Occidente con la caída de Constantinopla y ponen en práctica lo aprendido traduciendo. [...] Se consideraban en cierto modo miembros de un grupo de iniciados con el poder de hacer accesibles a un público más amplio los tesoros de la lengua griega, de satisfacer la creciente demanda de una sociedad ávida de revivir a los clásicos» (2000: 29).

21. Las traducciones de Bessarión, Decembrio o Bruni gozaron de una amplia difusión en el panorama español de la época. Véase González Rolán, Moreno y Saquero (2000). Y para un panorama general sobre el humanismo italiano en España, Gómez Moreno (1994).

22. Parece que la mayor parte de las traducciones que de Apiano se realizaron en España derivan no de esta versión latina de Pier Candido Decembrio, sino de la italiana de Braccio. Así lo atestigua el análisis comparativo entre estas obras que realiza Bravo (1975: 35-37). 


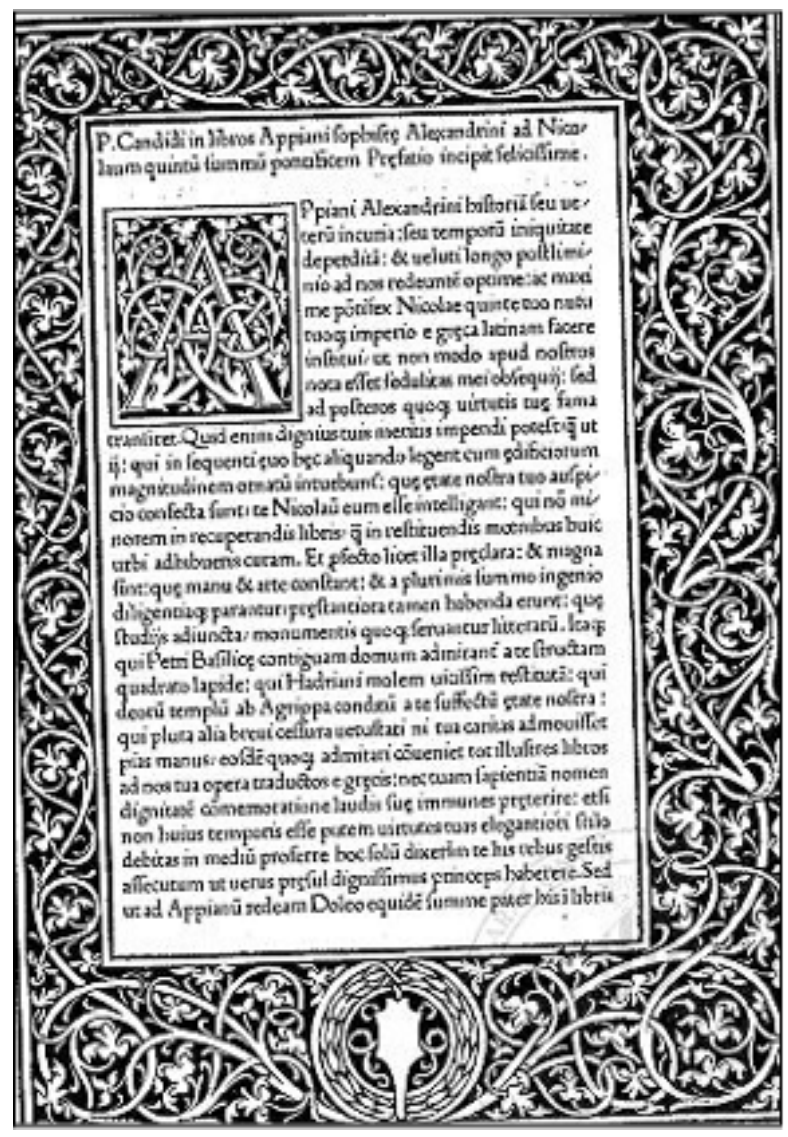

Fig. 1

Fue la obra de referencia, incluso tras la aparición de la editio princeps griega publicada en Basilea por Charles Estienne el 1551. A partir de ella, de entre las primeras versiones de Apiano en lengua vernácula se encuentra la traducción al italiano de Alessandro Braccio (Italia, 1519); al francés, la traducción de Claude de Seyssel de 1515, que permaneció inédita hasta 1544; y conservamos una versión inglesa, de 1578.

Pier Candido Decembrio difundió asimismo en latín, la obra griega de Homero, Platón y Jenofonte, e hizo, además, una inmensa labor divulgativa de ciertos autores latinos como César, Quinto Curcio, Plutarco o Séneca, traduciéndolos al italiano ${ }^{23}$. Su traducción más popular quizás fue la Historia de Alejandro Magno, como atestiguan los numerosos manuscritos conservados ${ }^{24}$. Decembrio estuvo relacionado con numerosos personajes hispanos, como Iñigo López de Mendoza —el marqués de Santillana— o Nuño de Guzmán. Asimismo, estuvo vinculado a la corte de Juan

23. Nació entre 1392 y 1399 en Pavía. De su padre (también escritor) adquirió el interés por las letras griegas y latinas. Pronto se trasladó su familia a Milán y, con su hermano Ángel, a Génova. Desempeñó el cargo de secretario de Felipe María Visconti desde 1419 hasta 1447. Durante seis años (desde 1450 a 1456) fue brevium magister del Papa Nicolás V y de Calixto III, su sucesor. Y estuvo tres años en la corte del rey Alfonso v en Nápoles y de su sucesor, Fernando, más tarde. En vano intentó volver a trabajar junto al Papa; no lo consiguió. Murió en Milán en 1474.

24. Decembrio hizo la traducción de esta obra de Quinto Curcio Rufo al italiano para Filippo Maria Visconti, que no era docto en latín. Introdujo, para completar las lagunas de información que Curcio Rufo presenta, pasajes de las Vidas de Plutarco. Este es un indicador de que Decembrio usaba obras de distinta procedencia para hacer sus traducciones (Bravo, 1977; Moll, 1992). 
II de Castilla y la corte de Alfonso v en Nápoles ${ }^{25}$. Formaron parte de la corte del Magnánimo grandes humanistas como Lorenzo Valla, Bartolomeo Fazio y Antonio Beccadelli, el Panormita. El contacto de las cortes italianas con las del resto de Europa, así como las relaciones del propio Pier Candido con figuras relevantes del saber y las letras de su tiempo, explican que muchas de las traducciones de este y obras originales tuvieran una amplia difusión y prestigio ${ }^{26}$. Decembrio había traducido la obra de Apiano por encargo de Nicolás V, como hemos indicado, pero después de la muerte del Papa, al tener que buscar un nuevo protector, se la dedicó al rey Alfonso $\mathrm{v}$ de Aragón para recuperar el favor perdido de los Sforza (Fig. 2) ${ }^{27}$. La elección de esta obra se puede justificar por el elogio indudable y constante que Apiano realiza a la monarquía romana, elogio perfectamente extrapolable a los reyes humanistas, destacando entre ellos el rey Magnánimo: «In hunc igitur modum variis ex dissensionibus Romanorum Respublica ad concordiam tandem monarquiamque pervenit $\gg^{28}$.

25. La faceta aragonesa ha sido estudiada por Rovira (1990). Sobre la popularidad de Decembrio comenta Kristeller: «a well-know and respectable, if not famous, scholar and writer, and probably the most important representative of humanism in Milan during the first half of the fifteenth century» (1966: 358). En una línea semejante, también Bravo: «la figura de Pier Candido Decembrio, uno de los humanistas más famosos durante la primera mitad del siglo XV, no necesita presentación especial, dada su importancia, las relaciones de variado tipo que mantuvo con España y los precisos estudios que le han sido consagrados por la erudición filológica» (1977: 143).

26. Para más información sobre Pier Candido Decembrio, en especial en relación con España, véase, sin entrar en los estudios más clásicos: Ditt (1992-1993), Kristeller (1966), Lucía Megías (1992), Moll (1992), Matterni (2012) y Valero (2017), donde se encontrarán las referencias más relevantes, actualizadas con nuevas aportaciones.

27. La traducción sería: «en resumen, de ese modo desde las diversas disputas el estado de los Romanos llegó finalmente a la monarquía y a la concordia». (Traducimos res publica como «estado» en tanto que sentido etimológico de la expresión, aunque, siendo fieles a la realidad histórica a la que se hace referencia, podríamos indicar «república»).

28. La traducción de Decembrio es enormemente relevante porque, de no ser por ella, no podríamos conocer el contenido la Historia de Apiano, puesto que el manuscrito griego que utilizó para hacer su traducción se ha perdido. Este hecho hace que todavía sea más importante el manuscrito que se conserva en la Biblioteca de la Universitat de València, único de esta obra (mss., n. ${ }^{\circ} 830$ ). La obra tiene el número 100 en el Catálogo de Gutiérrez del Caño (1913-1914). El manuscrito consta de 224 páginas de vitela, a 25 líneas de 0,288 de alto por 0,208 de ancho, con una caja de escritura de 0,186 x 0,112. La letra es del siglo Xv. Véase De Marinis (1947-1952, I: 12) y Bravo (1975: 32). BH Inc. 116 Historia Romana [latine], cuyo título completo es a Petro Candido Decembrio traducta, Venetiis: Bernardus Pictor, Erhardus Ratdolt et Petrus Loeslin, 1477 (Fig. 2). 


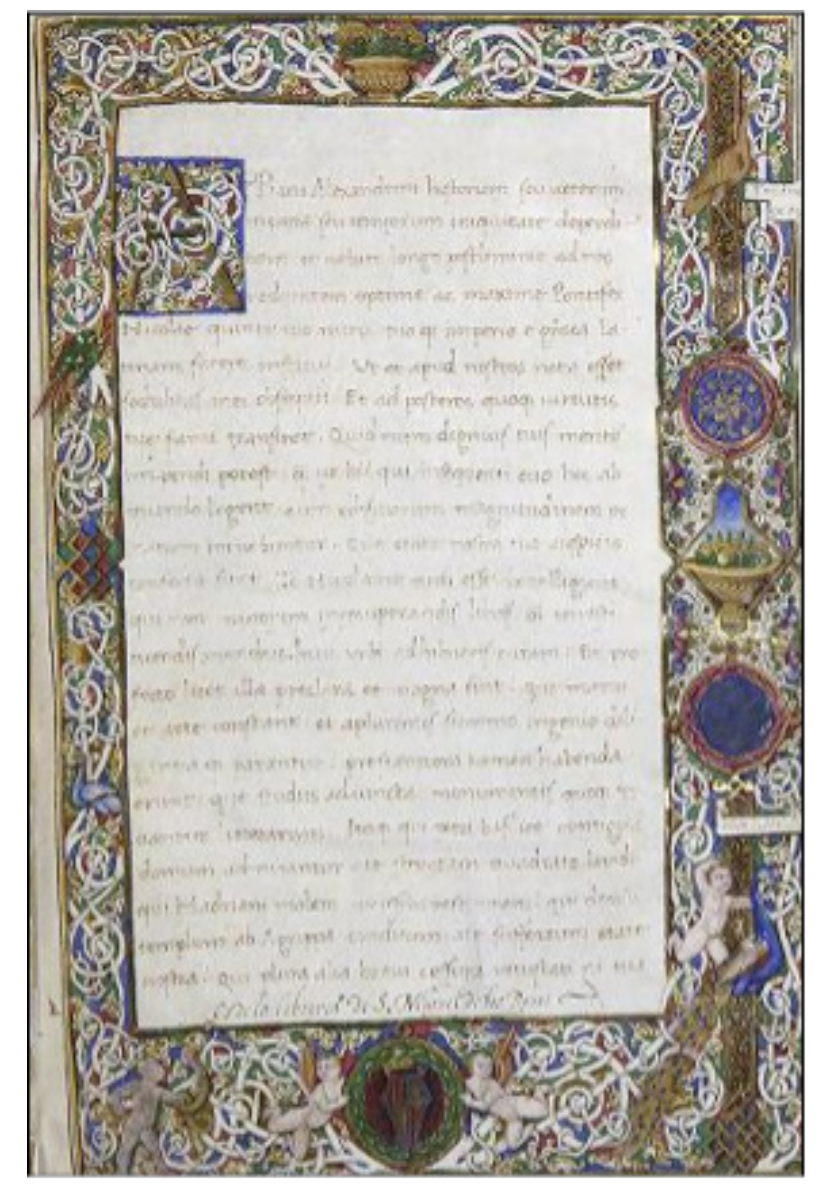

Fig. 2

\section{Juan de Molina, traductor de Los Triumphos de Apiano}

Juan de Molina fue un letrado originario de Ciudad Real, pero instalado en Valencia, en cuyos círculos cortesanos y literarios lo encontramos mencionado entre 1515 y $1550^{29}$. Su labor de traductor es quizás la más destacada, pero se movió en muchos otros ámbitos ligados a la difusión intelectual y al mercado de la imprenta, desde la corrección hasta la edición de textos. Tradujo, entre otras, las Epistolas morales de San Jerónimo (1520), Los Triumphos de Apiano (1522), la Crónica d'Aragón de Lucio Marineo Sículo (1524), el Libro de los hechos y dichos del rey Don Alonso de Antonio Beccadelli (1527), el Sermón en loor del matrimonio de Erasmo (1528) o las Homilías de Alcuino (1552). Participó en la edición de obras de materia edificante, como el Enquiridión de Erasmo (1528) o el Libro áureo de Marco Aurelio de Antonio de Guevara (1528). Pérez Priego ha destacado la labor de Molina en su conjunto como la de un: «traductor de oficio, hábil romanceador, [que] concibe la traducción, no como una compleja labor filológica, ni como una inquieta creación artística, sino como una pura actividad vulgarizadora» (1981: 39-40). Y en concreto, como señala el mismo crítico al considerar su elección de traducir a Apiano, las traducciones son 
necesariamente productos históricos que testimonian las corrientes culturales, ideológicas y literarias de una época. Las demandas de un tipo concreto de público, los intereses editoriales y los otros modelos literarios contemporáneos determinan, por tanto, la realización de unas traducciones y no otras ${ }^{30}$.

No sabemos hasta qué punto Juan de Molina llegaba a traducir, retocar o modificar totalmente los textos traducidos. En el caso que nos ocupa, podemos comprobar que la traducción de Los Triumphos de Apiano es casi totalmente literal. Aunque no hayamos podido realizar un cotejo exhaustivo, veamos un ejemplo representativo:

\section{Texto de Decembrio}

Ea ex causa primu[m] risus inter phoenices ottus rei exilitate demū qui huius modi foret astus scire cupientes potissimu[m] $\mathrm{cu}[\mathrm{m}]$ ambigere $[\mathrm{n}] \mathrm{t}$ quemadmodu[m] ciuitas tam angusto spacio includi posset co[n]cessuros se iureiura[n]do firmauere. (f. $7 \mathrm{v}$ )

\section{Texto de Juan de Molina}

Vista/ la manera dema[n]da ser de tan po/ca cosa al principio los Phenices se/ reyan: finalmente deseaua[n] saber que/ astucia o ardid era este: enespecial q[ue]/ dudauan como era possible $\mathrm{q}[\mathrm{ue}]$ una ciu/dad pudiesse ser ençerrada en tan pe/queño espacio: de suerte q[ue] con jura-mento les otorgaro[n] la dema[n]da. (f. 13r)

Sin embargo, lo cierto es que su intervención en algunas otras obras fue más lejos de lo que consideraríamos literalidad o siquiera aproximación al original. Así, Arronis (2013) ha demostrado que otra obra, supuestamente traducida de Molina, el Vergel de Nuestra Señora, no se trata solo de una simple traducción — como se creía y como él mismo reconoce- de la Vida de la Sacratíssima Verge Maria escrita originalmente en catalán por el valenciano Miquel Peres. Molina va mucho más allá de la traslación y la convierte en una composición totalmente nueva (Arronis, 2013). Tanto por esa cualidad recreadora o revisora, como por su evidente buen conocimiento del italiano, del catalán y del castellano, se puede sospechar que su labor fuera, por tanto, más activa y creativa que de mero traslado literal, y que pudiera, si no componer, sí «recomponer» textos heredados, de manera que resultaran realmente originales. Sin embargo, en el caso que nos ocupa, insistimos en que Molina, como acabamos de ver, traduce con estricta fidelidad la obra de Apiano. Eso sí, no recoge toda la obra del historiador alejandrino, sino que se limita a trasladar los episodios bélicos de las guerras cartaginesa, líbica, pártica y mitridática (libros VIII, X, XI y XII de su Historia Romana). Y su traducción no se sustenta sobre el texto griego original, sino sobre la versión latina de Pier Cándido Decembrio.

En lo referido a la labor no estrictamente traductora, y específicamente a la vinculada con la literatura de caballerías, conocemos que Molina intervino no solo en la edición de un libro de caballerías anónimo, Arderique (Valencia, Juan Viñao, 1517) 31 $^{31}$ sino también en la de Lepolemo

30. Pérez Priego sostiene literalmente: «las ideas dominantes, el público y el destinatario inmediato (patrocinador, mecenas, valedor), los intereses editoriales, los usos lingüísticos, los esquemas y modelos literarios, la propia tradición traductora, etc., son factores que condicionan de manera decisiva la práctica de traducir» (1981:35).

31. Arderique es el título de un libro de caballerías castellano anónimo que publicó Juan Viñao en Valencia, 1517. De esta edición, la única que conocemos, se conservan tres ejemplares — véase la página de Tipobibliografía valenciana (Canet, 2018) [consultada en 19/05/2021] —.El libro fue reeditado por Carpenter (2000), y su resumen se puede consultar en la Guía caballeresca correspondiente (Carpenter, 1999). En su versión castellana, la única que conocemos, se terminó de imprimir en Valencia, el 8 de mayo de 1517. La edición nada nos dice sobre el autor o posible traductor del Arderique, pero sí que nos proporciona, en cambio, antes de la Tabla capitular, justificando la fe de erratas, el dato importante de que «El bachiller Juan de Molina [fue] corrector de las presente impressión, y traductor» (Carpenter, 2000b: 211). Véase, para una bibliografía más actualizada, así como para el contexto y temática de la obra, el trabajo de Beltrán (2019b). 
o El caballero de la Cruz (Valencia, Joan Jofre, 1521), obra atribuida al desconocido Alonso de $S_{\text {Salazar }}{ }^{32}$. Interesa destacar esa faceta de corrector de libros de caballerías porque, como veremos al examinar la «Epístola prohemial» a Los Triumphos de Apiano, Molina es el primer crítico humanista - antes incluso que Juan Luis Vives - que ataca las ficciones caballerescas (Amadís, Esplandián y Tirant), en cuyas ediciones, sin embargo, como acabamos de comprobar, está participando en esos mismos años. Molina sería, además, con toda probabilidad, un personaje popular en la corte virreinal. Así lo denota su presencia en la Jornada Sexta de El cortesano de Luis Milán (2010), donde interviene en jugosos diálogos y donde se llegan a burlar de su locuacidad, apodándolo «bachiller Cigala» («cigarra»). ${ }^{33}$

\section{El marco de la «Epístola prohemial»: entre el título, la justificación y el ataque a los libros de caballerías}

La «Epístola» a la traducción de Los Triumphos de Apiano se enmarca entre una serie de elementos paratextuales a los que conviene prestar atención ${ }^{34}$. En primer lugar, sin duda la bella portada, decorada con colores brillantes, con el escudo de la familia de Mendoza que ocupa la mayor parte del espacio del folio (Fig. 3). Una corona triunfal de laurel, de color verde oscuro, ornada con flores y lazos, rodea el escudo, dividido en cuarteles, donde aparecen las expresiones latinas habituales con la salutación evangélica: AVE MARIA y GRATIA PLENA. El escudo está coronado por una corona de color dorado y rojo, rematada con piedras preciosas que parecen rubíes. Rodean el blasón cuatro atributos épicos para el marqués: VALENTIAE ET INDE HISPANIAE SERVATORI, PACIS FUNDATORE, CIVIVM PROTECTORE Y HOSTIVM PROPULSORI. En la parte inferior del folio aparece el título de la obra con letras mayúsculas rojas rodeadas por una cenefa rosa. En la superior, el nombre del marqués: MARCHIONI D. RODERICO DE MENDOZA.

32. Alonso de Salazar aparece como autor en la primera edición del Lepolemo, pero desaparece en las siguientes. Juan de Molina contribuyó a la financiación de la primera edición de este libro («dando lo necessario para ello el bachiller Juan de Molina») y aparece como revisor en la segunda (1525): «fue mejorado [el libro] y de nuevo reconocido por el bachiller Molina» (Bognolo, 2002; y Neri, 2006: 7-8).

33. Véase, a este propósito, el trabajo sobre El cortesano de Castaño (2018), con bibliografía al respecto.

34. Todas las referencias que hagamos a continuación serán a partir del ejemplar de Los Triumphos que se conserva en la Biblioteca Histórica de la Universitat de València. Para realizar nuestro trabajo nos hemos servido de la copia digitalizada: http:/ /bivaldi.gva.es/ es/consulta/registro.cmd?id=3170 [consultada en 19/05/2021]. El ejemplar, de 144 fs., está descrito en la Tipobliografía valenciana de la base de datos de Parnaseo (Canet, 2018): http://parnaseo.uves/imprenta/publicacion/presentacion.html\# [consultada en 19/05/2021] 


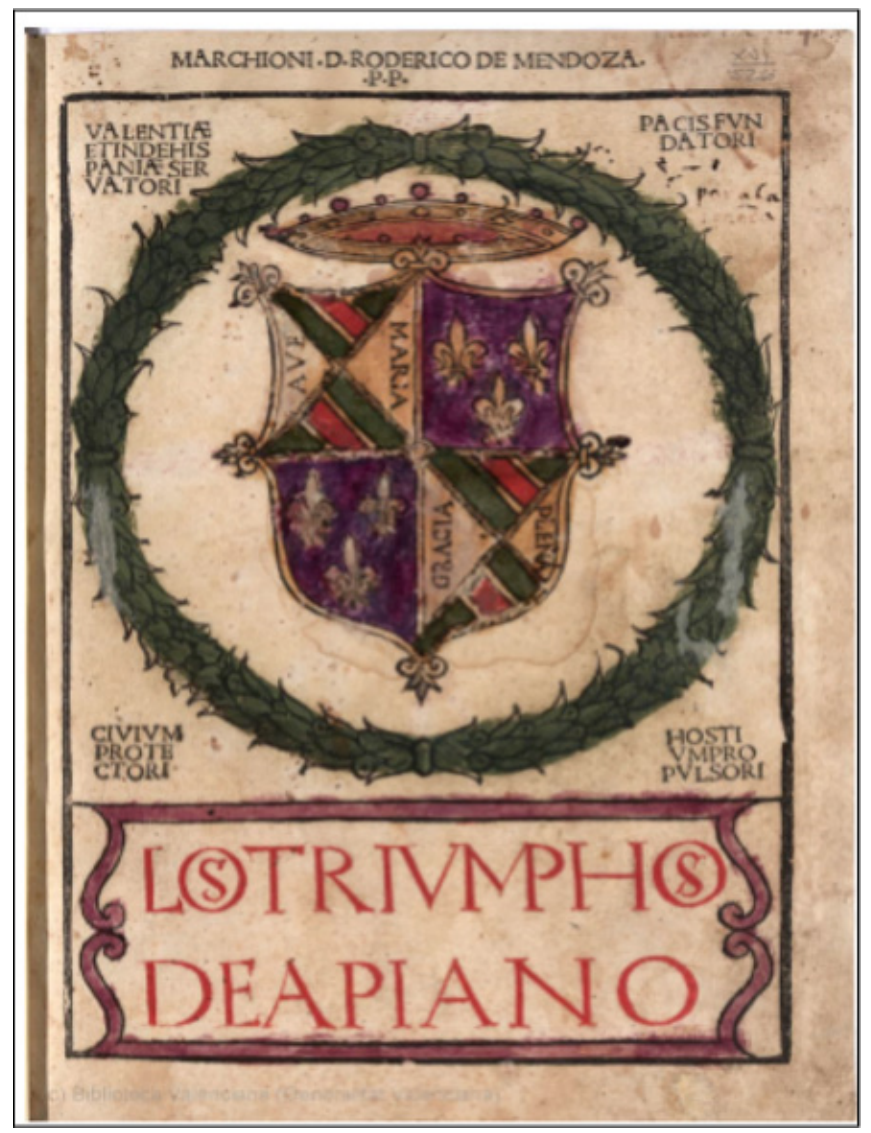

Fig. 3

El título de la obra de Molina se presenta como Los Triumphos de Apiano, recogiendo dos de las acepciones actuales — la séptima y octava- de este término en el DRAE: «entrada solemne» $\mathrm{y} \ll$ obra de arte que exalta la victoria de un personaje.... ${ }^{35}$. El autor se estaba refiriendo a «triunfo» en un sentido histórico (pasado y presente), ceremonial y también literario. Resonaban los Triomfi poéticos de Petrarca, pero sobre todo los Triomfi de los espectaculares desfiles militares, entradas o salidas (por los famosos arcos o puertas de Triunfo) de personajes egregios de la Antigüedad como Julio César, Escipión Africano o Pompeyo, revitalizados por monarcas protectores de humanistas en el XV, como Alfonso el Magnánimo (baste recordar el arco de triunfo de Castel Nuovo en Nápoles), y recreados en conjuntos arquitectónicos o pictóricos, como, por ejemplo, los de los tapices de Andrea Mantegna sobre los Triunfos de César.

Tras el título, a modo de dedicatoria, nos encontramos con la extensa «Epístola prohemial» (fols. 1-17), en la que nos vamos a detener más adelante: una prolongada laudatio a la figura de Rodrigo de Mendoza, marqués del Cenete, centrada en su comportamiento como dirigente del aplacamiento de la guerra de Germanías. ${ }^{36}$

35. DRAE: [7] «En la antigua Roma, entrada solemne en la ciudad de un general vencedor con su ejército»; $[8]$ «Obra de arte que representa un triunfo romano, y, en general, la que exalta la victoria de un personaje histórico, bíblico o mitológico, o, alegóricamente, de una virtud cristiana. Triunfo de Maximiliano, de Galatea, de la fe».

36. Para la biografía de Rodrigo de Mendoza es absolutamente imprescindible el libro reciente de Ferrer del Río (2020). La autora, además de ordenar y completar los datos de su agitada vida, destaca y reivindica una intensa y continuada labor como coleccionista y patrocinador de libros y proyectos artísticos, que hace que la personalidad del marqués del Cenete destaque como una de las más 


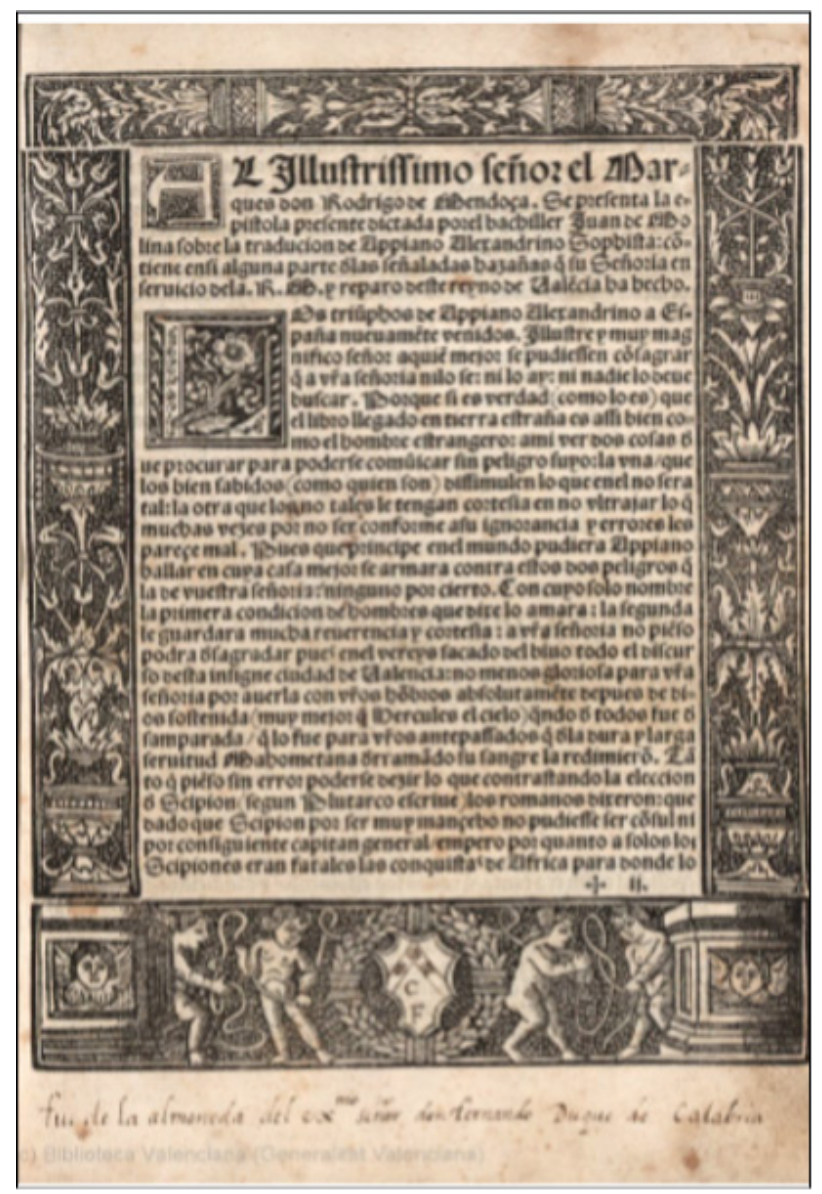

Fig. 4

El primer folio, con su dedicatoria «Al Illustrissimo señor el Marqués don Rodrigo de Mendoza», se encuentra orlado, con orlas habituales en la imprenta de la época y en particular en la de Joan Jofre (Fig. 4). En la parte inferior del folio encontramos cuatro ángeles, que parecen semidesnudos, dos a cada lado de la corona de laurel y completan la escena, como si llevaran las cintas que rematan la corona triunfal. Dentro de la corona hay un escudo simplificado, en el que están inscritas dos letras $\mathrm{C}$ y F, de las que desconocemos el significado. Asimismo, la capitular del epígrafe del capítulo, así como la primera del texto propiamente dicho también aparecen decoradas, sobre todo esta última, que incluye una flor como acompañamiento de la letra L, siguiendo la tipografía de Jofre. Es una constante en toda la obra, como en la mayoría de las del impresor valenciano, la caligrafía esmerada en las letras capitales:
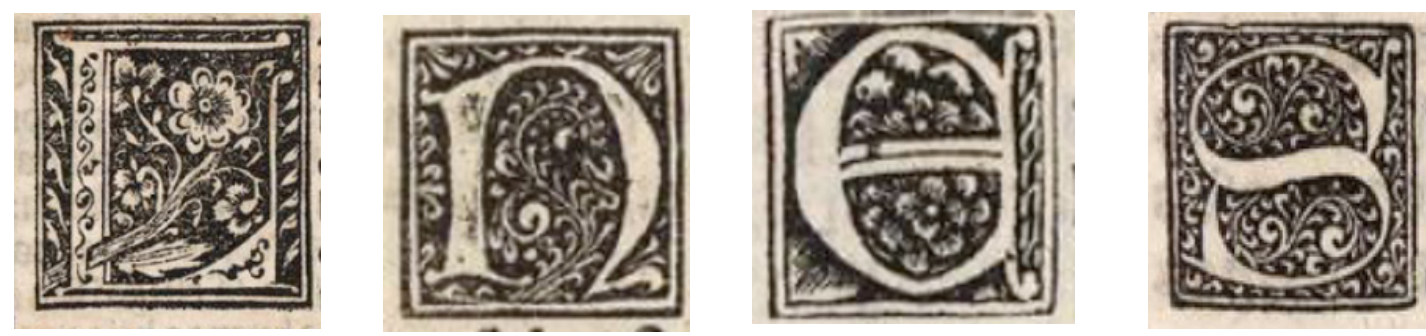

Fig. 5

relevantes culturalmente en su tiempo. El libro es un completo y detallado recuento de hechos, cotejo documental exhaustivo y análisis, en su contexto histórico, de cada uno de los pasos de su biografía; además, un rico acopio de ilustraciones, incluidas las del rostro del marqués; finalmente, una más que abundante bibliografía. 
Tras la «Epístola prohemial»y en el capítulo «Argumento sobre el mesmo libro», a partir del fol. 17, se incluirá lo que la retórica clásica denomina un accessus ad auctorem, es decir, una justificación introductoria sobre los porqués de la escritura - o traducción - de la obra que se presenta. Molina, parte de la plantilla del accessus, pero explica con suma originalidad que es muy común que quienes quieren comprar un libro estén indecisos, y primero lo hojeen (mirando el autor y su argumento), antes de decidir si quieren adquirirlo o no. Es por lo que, para convencer al futuro lector, resuelve introducir unas notas sobre la personalidad de Apiano, argumentando que fue un historiador destacado (la metáfora «águila volante», que vemos en la cita para singularizarlo, podría ser imagen extraída de la iconografía heráldica, si bien no necesariamente), porque fue fiel a la verdad ${ }^{37}$ :

Doctíssimo en las letras griegas. Natural de Alexandría y por esto dicho Alexandrino, llamado otrosí sophista. Este, como sus obras muestran (puesto que las más se perdieron), fue águila volante entre los historiadores. Assí en escreuir muchas cosas y tratarlas por muy buen estilo, como también (lo que más precioso es) en aver guardado verdad en su escrevir quanto ningún historiador. (f. 17, 1. 36-40)

Introduce ahora Molina la crítica a las novelas de caballerías en tanto que obras fantasiosas que atacan a la verdad. Su obra, en efecto, sigue justificando, tiene este criterio de veracidad como base fundamental, y no las «ficciones ventosas», los «humos escuros y espessas nieblas», los «vanos tronidos y estruendos fantástigos» $\mathrm{ni}$ «los encantamientos mintrosos»:

No están aquí las ficciones ventosas de Esplandián, ni las espumas de Amadís, ni los humos escuros y espessas nieblas de Tirante, ni los vanos tronidos y estruendos fantástigos de Tristán y Lançarote: ni los encantamientos mintrosos que en estos libros que he dicho y otros como ellos falsamente se leen. Los quales todos (como Petrarca muy bien dize) hinchen las cartas de sueños. (f. 19, 1. 5-10)

Aquí, Molina extiende a Amadís, Esplandián y Tirant la censura que ya Petrarca - a quien, como leemos, explícitamente cita - hacía de las ficciones artúricas (Tristán y Lanzarote), precisamente en uno de sus «Trionfi»: «ecco quei che le carte empion di sogni, Lancilotto, Tristano e degli altri erranti» (Triumphus Cupidinis, III, vv. 79-81). De lo dicho se desprende la importancia que le concede Molina a la historia entendida como lux veritatis (Cicerón), como testigo fiel de la realidad acaecida. Pero su afirmación, entre la de Petrarca y la más conocida de Luis Vives, queda, además, como un intento de elevar la importancia de su obra, menospreciando la de los vulgares competidores en el favor del público, los autores de libros de caballerías.

Años más tarde, en la dedicatoria de la traducción que el mismo Juan de Molina realizó de las Homilías atribuidas a Alcuino de York, publicadas en 1552, el valenciano utilizará el mismo tópico para el exordio, incluyendo incluso de nuevo la cita de Petrarca:

Tanto era el deseo que las gentes tenían de un semejante libro, que por librarse ya de Amadises, Esplandianes, Tristanes, Lançarotes, Epístolas, Sonetos, Capítulos y otras burlerías llenas de vanidad, que como Petrarca dize hinchen las cartas de sueños, por más no poder se han abraçado con un libro que conúnmente llaman Epístolas y Evangelios en castellano. (f. xvi r) $)^{38}$

37. Como insistirá más adelante, quienes no fíen o no tengan suficiente con esa escueta información biográfica proporcionada, la podrán comprobar y ampliar en otros múltiples documentos y a través de otras reputadas opiniones (f. 18, 1. 1-3).

38. Y, sin embargo, ha desaparecido ya Tirante, con sus «humos escuros y espessas nieblas». Véase, para el contexto de todas estas menciones dentro de la tradición de críticas de los humanistas a los libros de caballerías, Beltrán (2019a). 
Pero volviendo atrás, dos años después de la primera condena de Molina, Luis Vives escribe en De institutione feminae christianae (1524), en el quinto capítulo, que versa sobre los escritores que deben ser leídos o no por las mujeres («Qui non legendi scriptores qui legendi»), la siguiente lista de «pestiferi libri»:

Hoc ergo curare leges et magistratus congruit. Tum et de pestiferis libris, cuiusmodi sunt in Hispania Amadisus, Splandianus, Florisandus, Tirantus, Tristanus, quarum ineptiarum nullus est finis [...]: Celestina lena, nequitiarum parens; Carcer amorum. In Gallia Lancilotus a lacu, Paris et Vienna, Ponthus et Sidonia, Petrus Provincialis et Magalona, Melusina, dona inexorabilis. In hac Belgica Florius et Albus flos, Leonella et Canamorus, Turias et Floreta, Piramus et Thisbe ${ }^{39}$.

La obra de Molina traduce, en efecto, a diferencia de estos libros fabulosos, hechos verdaderos. Por tanto, lo que el lector hallará son historias con «muy entera fieldad escritas» (f. 18, 1. 11). Prosigue Molina, en anticipatio (otro requisito retórico del exordio), describiendo los cuatro capítulos de su obra ( «quatro conquistas señalas que entre otras los romanos touieron con estrangeras naciones»): el triunfo africano (la guerra con los cartagineses que califica de «primera y principal»); el triunfo sirio (contra Antíoco, rey de Siria), el triunfo pártico (contra Drodes, rey de los partos) y el triunfo mitridático (contra Mitrídates, rey de Ponto) (f. 18, 1. 4-8, 13-14). En cuanto al autor de la obra traducida, Molina informa:

Apiano de Alexandria escrivió en griego en el tiempo de Adriano, emperador avrá mil quatrocientos y sesenta años; escrivió, como él mismo testifica, las historias de los romanos en XXII libros, de los quales por culpa del tiempo no se hallan sino nueve: estos quatro de las guerras externas, cinco de las guerras civiles, con otros dos tratadillos breves que algunos en cuenta de libros ponen, que son el Ilirio y Céltico. De todo esto, plaziendo a nuestro señor, hablaremos más largas quando vengamos en la traducción de las guerras civiles.

Por tanto, Molina se proponía, además de los cuatro libros de las guerras externas (VIII, XI [en 2 libros] y XII), traducir más adelante («hablaremos más largas») los cinco de las guerras civiles (XIII, XIV, XV, XVI y XVII), es decir, los cinco que se supone que Alonso de Maldonado había traducido ya (pero que se han perdido), hacia 1460, tal como se afirma en el prólogo a la Vida o Hechos de Alonso de Monroy: «Prólogo que hizo Alonso de Maldonado sobre la traducción que hizo de latín en romance de los cinco libros de Apiano Alejandrino sobre las guerras civiles, intitulados al muy ilustre señor don Alonso de Monroy, maestre de Alcántara ${ }^{40}$.

Molina comenta, finalmente, las ventajas de su labor divulgadora al traducir una obra como la de Apiano. Es el propio autor quien apunta que su traducción no es de la lengua griega, la original de Apiano, sino de una latina. Así pues, establece un símil entre su falta de comprensión de la lengua griega y el desconocimiento que tienen otros del latín. Es por lo que traduce el texto en lengua latina a una lengua vulgar, para que la conozca un amplio público:

39. De institutione feminae christianae (1524) es un texto dedicado a Catalina de Aragón, reina de Inglaterra, aunque en realidad escrito para ayudar a la educación de su hija, la joven princesa María, la futura María I de Inglaterra, de siete años de edad. De familia judía, conversa, tuvo que estudiar en París y residir entre Brujas, Lovaina, Oxford y Londres. Hay que leer en su contexto pedagógico las citas del gran humanista, filósofo y pedagogo valenciano, amigo de Erasmo de Rotterdam y una de las personalidades principales del humanismo europeo del siglo xvi.

40. Romero (1978: 47). Puede que Molina conociera esa traducción anterior y que no prosiguiera la traducción del resto de los libros por el fallecimiento del dedicatario, Rodrigo de Mendoza. 
No pienso que menos reconoçerán el beneficio que de mis trabajos reciben los que no saben latín ni saberlo esperan, que yo y otros reconoçemos a los que de griego en latín nos passan estos libros. Porque pues ignoramos las letras griegas para siempre careçeríemos deste fruto exçelente, sino por el trabajo que passan estos notables varones que las letras griegas alcançan. Y essa mesma cuenta podrán hazer comigo los legos a quien es el latín lo que a mí el griego, como creo que los cuerdos y gratos lo hacen. (f. 18, 1.26-32)

Es ahora Molina cuando introduce la primera (y la única) referencia al autor de la traducción al latín de la obra, Pier Candido Decembrio. Referencia muy errónea, puesto que habla de «Publio Candido». Además, apunta la labor de ordenación del texto con la intención de simplificar la lectura de la obra; con esta misma intención se puede justificar la presencia de los sumarios. Al exponer Molina que ha suprimido el prólogo de Decembrio por no considerarlo pertinente, está poniendo de manifiesto que en el resto de la obra, puesto que no señala otra cosa, ha sido fiel a la obra del italiano ${ }^{41}$.

Tras esta Introducción, en doble columna se expone el índice - cuatro folios - con cada uno de los capítulos de los libros que componen la obra (con la especificación de los folios) ${ }^{42}$. El encabezamiento de todos los folios del índice lleva la indicación «Tabla». A continuación, da comienzo la obra propiamente dicha con el primero de los capítulos, que trata sobre el origen de Cartago como ciudad.

\section{La «Epístola prohemial»: elogio biográfico al marqués del Cenete y crónica de una guerra}

La traducción de Los Triumphos de Apiano por Juan de Molina comienza, como hemos indicado, con una «Epístola prohemial» de considerable extensión (17 folios), en la que el traductor realiza un elogio sostenido a la figura de Rodrigo de Mendoza, marqués del Cenete. Juan de Molina ya había hecho preceder una traducción anterior suya, la de las Epistolas de S. Hyeronimo: nuevamente traducidas del latín en lengua castellana... (Valencia, Joan Jofre, 1520), de una «Epístola proemial», dirigida en este caso a María Enríquez de Luna (1474-1539) primera duquesa de Gandía, que se retiraría al final de su vida, llegando a ser abadesa del convento de Santa Clara de Gandía. Y, posteriormente, el Vergel de Nuestra Señora (Sevilla, Dominico de Robertis, 1542), supuesta traducción de la obra original de Miquel Peres, pero en realidad nueva obra, como demuestra Arronis (2013), también irá precedido de otra «Epístola proemial» (fols. 1v-4v), dirigida en este caso a la priora y religiosa del colegio de Santa Catalina de Siena de Granada. El sin-

\footnotetext{
41. «Digo que fue esta obra traduzida de griego en latín por Publio Cándido, exçelente varón en Italia en tiempo del Papa Nicolao Quinto, que avrá setenta años, ahora viene a la lengua castellana no solo traduzida, mas aun partida en capítulos y sumarios dellos para que el lector mejor lo entienda y goze. Dexé de poner el prólogo del mesmo autor, porque no me pareció que hazíe al caso ni tiníe gusto ni provecho para los que comunmente se deleytan en estos libros de romançe» (f. 18, 1.37-42). «Setenta años», en efecto, como afirma Molina, tendría la traducción de Decembrio hacia 1522, puesto que se calcula que fue terminada hacia 1452. De forma errónea afirma Bravo que Molina no indica que usa una versión latina para traducir su obra (1975: 34), cuando sí lo hace, como ha podido comprobarse en el texto antes citado.

42. Los capítulos se muestran organizados según el orden de aparición y con la abreviatura «cap.» antes de la indicación numérica (en números romanos) que precede a cada capítulo. Por indicar un ejemplo: «Cap[ítulo] i pone la fundación de Cartago y como su estado y señorío començó. fo.j» (f. 19,1.3-4). El hecho de especificar el tema que se va a tratar (como ya había hecho con la «Epístola proemial») podemos pensar que se realiza con la intención de crear una obra sistemática, ordenada y clara. El primer libro tiene cuarenta y ocho capítulos; el segundo, veintiséis; el tercero treinta y dos; y el cuarto, cuarenta y cuatro.
} 
tagma «Epístola prohemial», sin ser extraño, no resulta habitual ${ }^{43}$. Lo encontramos previamente utilizado por el humanista Angelo Poliziano —en italiano, como «Epistola proemiale»— para anteponer un texto (más breve y teórico que el de Molina) a la Raccolta aragonese, un importante cancionero que Lorenzo de Médici, el Magnífico, hizo recoger para ofrecérselo a Federico, hijo de Alfonso el Magnánimo ${ }^{44}$. Sin embargo, la «Epístola prohemial» de Molina, a diferencia de la de Poliziano y de las otras del propio Molina, es tan extensa que incluso incluye al final un epílogo a modo de resumen de todo lo dicho (fol. 15). ${ }^{45}$

De hecho, esta «Epístola» sobrepasa los límites habituales de una dedicatoria, prólogo o introducción convencionales, para convertirse en una crónica laudatoria o biografía parcial, puesto que integra, ordenados cronológicamente, una serie de episodios de la vida del marqués del Cenete, desde la perspectiva del marqués como protagonista, y relacionados con su lucha en Valencia contra los llamados agermanados, entre 1520 y 1522. La de Germanías valencianas es la denominación clásica que dan los historiadores al conjunto de hechos históricos que tuvieron lugar, entre los años 1519 y 1522, a partir del momento en que una serie de representantes de los gremios del cap i casal del Reino, apoyados por miembros de la baja nobleza, pretendieron hacerse con el control del gobierno municipal, lo que originaría una brutal represión monárquica. El conflicto se daría por finalizado en marzo de 1522 al ser ajusticiado uno de sus principales dirigentes, Vicent Peris.

El descontento social y político había empezado a partir de la revuelta gremial, que se produjo por las pestes acontecidas en Valencia durante 1508, cuando el temor al contagio había provocado la huida de los gobernantes, dando lugar a un vacío de poder de varios años. Durante este tiempo, gran parte de la oligarquía dirigente malversó el capital que la monarquía asignaba para el gobierno de la ciudad. A todo ello se unió la escasez de trigo tras años de malas cosechas y que obligó a importarlo de Nápoles, lo que propició el aumento de piratas que robaban los cargamentos que se acercaban al puerto valenciano. Como el abastecimiento de la ciudad y la situación de desamparo iban en aumento, en septiembre de 1519 los gremios (más de dos mil gremios constituían la parte esencial de la economía de Valencia) tomaron la decisión de actuar contra los ataques corsarios. Una serie de líderes, como Joan Llorenç, fueron adquiriendo progresivamente relevancia, creando la llamada «Junta dels Tretze», órgano de máxima autoridad dirigente de los gremios independiente de la administración real y municipal. La independencia y rebeldía terminó por desembocar en enfrentamientos cada vez más enconados y en una guerra abierta declarada contra el virrey de Valencia, Diego Hurtado de Mendoza (hermano de Rodrigo de Mendoza, marqués del Cenete), como representante real en la ciudad. El principal objetivo de los agermanados era conseguir el control del gobierno municipal y del Consell de la ciudad. Cuando Joan Llorenç murió, otros cabecillas de la revuelta, como Joan Caro, Guillem Sorolla, Bertomeu Monfort y Vicent Peris, trataron de seguir su ejemplo. La revuelta fue sofocada con rapidez por un ejército real organizado frente a unos grupos gremiales sin dirección militar, sin caballería, sin estrategia, y con escasez de recursos que obligaba a los batallones al saqueo para su sustento. Finalmente, cuando Vicent Peris fue ajusticiado, rápidamente fue restablecido el orden monárquico en la ciudad. La

\footnotetext{
43. Realmente, el traductor se refiere solo a una «Epístola», pero el editor, al disponer este paratexto, hace que encabece las páginas pares con esa «Epístola»y las impares con «prohemial», lo que conduce a leer en conjunto: «Epístola proemial».

44. Véase: http://blogs.dotnethell.it/artblog/19.-Epistola-Raccolta-aragonese-di-A.-Poliziano-testo-integrale__11824.aspx

45. No tiene que ver tampoco con la «Epístola proemial» que escribe unas décadas más tarde otro valenciano, Onofre Almudéver, para justificar su labor como editor, estudiada por Mahiques (2019).
} 
revuelta de las Germanías no fue un hecho aislado, puesto que casi al mismo tiempo se produjeron los levantamientos de los comuneros en Castilla, y otras rebeliones gremiales en Alemania y en otros lugares de Europa ${ }^{46}$.

Juan de Molina pone al marqués del Cenete como protagonista principal del sofocamiento del conflicto de las Germanías, destacando como heroica su actitud militar y ética. La loa constante de Molina a Mendoza se evidencia en los elogios repetidos y en el hecho de que describa con gran detallismo aquellas situaciones en las que el marqués demuestra su valor y bien hacer, y pase más por encima por aquellas que él no protagoniza (como cuando cuenta la muerte del Encubierto o de la marquesa, María de Fonseca). Asimismo, ejemplifica las virtudes militares del marqués mediante la exposición de tres episodios bélicos que pusieron en riesgo a la ciudad de Valencia: el motín organizado por Vicent Peris, el del Encubierto y el de Algeciras. Estos episodios están ordenados cronológicamente y se especifican en cada uno de ellos las fechas más relevantes ${ }^{47}$. En ese sentido, como crónica biográfica —es el primer relato completo que poseemos sobre los acontecimientos de las Germanías - y como texto laudatorio, esta «Epístola» a Mendoza y sobre Mendoza, se sitúa en la cadena que textos biográficos sobre un solo personaje, que había empezado en la literatura española, en el siglo xv, con la biografía de Pero Niño, conde de Buelna, El Victorial, continuado con la Crónica de don Álvaro de Luna y Los hechos del condestable Miguel Lucas de Iranzo, y seguido, en el reinado de los Reyes Católicos, con los Hechos del marqués de Cádiz y, sobre todo, con los Hechos de Alonso de Monroy, escritos por Alonso Maldonado.

Hay que diferenciar estas biografías de un solo personaje de las biografías colectivas, o series de retratos biográficos, como las Generaciones y semblanzas de Fernán Pérez de Guzmán, o los Claros varones de Castilla de Fernando del Pulgar. Y también diferenciarlas, claro está, de las crónicas oficiales, dedicadas a los sucesivos reyes de la Corona castellana. Los autores de todas estas biografías solían ser hombres letrados, como Juan de Molina, tal vez no grandes intelectuales, pero sí escritores con formación universitaria (a veces juristas o secretarios) o literaria (formación humanística básica), lo que les situaba en una peculiar situación o perspectiva de dependencia -económica, afectiva e incluso ética - respecto a sus biografiados. Sin embargo, de todas las biografías mencionadas es la última, la Crónica de Alonso de Monroy, la que interesa destacar especialmente, puesto que, como tal biografía, se presenta como «Prólogo que hizo Alonso de Maldonado sobre la traducción que hizo de latín en romance de los cinco libros de Apiano Alejandrino sobre las guerras civiles, intitulados al muy ilustre señor don Alonso de Monroy, maestre de Alcántara; pone su vida e historia». Es decir, es una crónica, de las mismas dimensiones aproximadamente que la del marqués del Cenete escrita por Molina y ambas se anteponen como prólogo a una obra histórica del mismo historiador, Apiano Alejandrino.

\begin{tabular}{|c|c|}
\hline Autor / Traductor & IO / BIOGRAFÍA \\
\hline Alonso de Maldonado, Historia de Alonso de Monroy & $\begin{array}{l}5 \text { libros de Apiano sobre las Guerras Civiles: } \\
\text { Libros XIII, XIV, XV, XVI y XVII } \\
\text { [Traducción perdida }]\end{array}$ \\
\hline Juan de Molina, Historia de Rodrigo de Mendoza & $\begin{array}{l}4 \text { libros de Apiano anteriores a las Guerras Civiles } \\
\qquad \begin{array}{c}\text { Libros VIII, XI (en } 2 \text { libros) y XII } \\
\text { [Traducción conservada }]\end{array}\end{array}$ \\
\hline
\end{tabular}

46. El estudio clásico sobre la revuelta es el de García (1975 y 1981).

47. Podríamos considerar que aquí se demuestra la voluntad de Molina de ser lo más objetivo y fiel a la realidad; lo más historiador «cientifíco» posible, entroncando así con la tradición historiográfica clásica, de historiadores como César o Salustio que hacían grandes especificaciones espaciales y temporales. 
Vamos a tratar de examinar la «Epístola prohemial» detenidamente, epígrafe por epígrafe, porque contiene claves esenciales para el entendimiento de la difusión de la traducción de Apiano en este momento (año 1522) y en este lugar (Valencia) concretos.

[A] Introducción:

En primer lugar, Molina empieza comparando a Rodrigo de Mendoza con Escipión y con el Cid, e indica que se propone relatar los acontecimientos que llevarían al marqués a ser el encargado de esgrimir el bastón de Justicia: los hechos sucedidos en Játiva y, posteriormente, las muertes de la marquesa, de Vicent Peris (llamado siempre «Pérez» en el texto), uno de los más destacados entre los agermanats, y del Encobert. La «Epístola», como vamos a comprobar, está cargada de dramatismo y detallismo en las descripciones de los pasajes bélicos; escrita con tensión, henchida de patetismo, sobre todo en aquellos episodios en los que se loa la serenidad y buen hacer de Mendoza en las situaciones de mayor peligro (como en los enfrentamientos de Sagunto o «Monviedro» [sic en el texto] $)^{48}$. Las comparaciones con personajes ilustres, tanto históricos, como bíblicos o mitológicos, como Hércules, Jonás, Quinto Curcio y Rodrigo Díaz de Vivar, el Cid Campeador, van a ser constantes, como también observaremos.

El primero de los folios está encuadrado por una orla, con una cenefa vegetal continua, que se extiende por todo el folio y que acaba con la base de dos columnas con el rostro de un ángel alado (en la parte inferior izquierda y derecha) ${ }^{49}$. En el párrafo inicial, siguiendo el requisito de la anticipatio en la retórica convencional del exordio, Molina adelanta y avisa de que va a tratar de exponer algunas de las hazañas que Mendoza ha realizado en servicio del rey y por Valencia: nadie tan ilustre y magnífico señor como él, «ni lo sé, ni lo hay, ni nadie lo deve buscar» (f. 1, 1. 9-11). Aludiendo implícitamente a la primera conquista de Valencia (que elogia, calificándola de «insigne»), es decir a la conquista del Cid, en el siglo XI, hace referencia a que gracias a los antepasados de Mendoza se salvó Valencia de la dura y larga servidumbre morisca: «derramando su sangre la redimieron». En efecto, Rodrigo Díaz de Vivar y Mendoza, I conde del Cid, llevaba a gala esa estirpe, a la que se hará referencia más de una vez.

Vuelve a la tradición romana, sacándola a colación de la labor de Mendoza y su familia, cuando cita, para elogiar a Mendoza, el caso de Escipión (f. 1, 1. 29-32). El autor indica que los romanos querían con tanto ahínco que Escipión fuera capitán del ejército (aun rompiendo leyes y estatutos), como los valencianos quisieron que lo fuera Mendoza. El hecho de remitir a la vida de Escipión (siguiendo a Plutarco) denota el conocimiento de Molina de las fuentes clásicas y de la historia romana. Continúa añadiendo que Dios y todos los ciudadanos de Valencia han sido testigos de su continua lucha: «han visto a vuestra señoría peleando en esta ciudad y reyno contra los rebeldes y enemigos del rey infinitas vezes puesto en peligro: y otras muchas aver seýdo herido, preso, maltratado y desacatado, no empero jamás averse dexado de su empresa ni buelto atrás» (f. 2, 1. 19-22).

[1] «La açeptación que el señor Marques hizo del bastón de cargo de Justicia» es el primer apartado de la crónica, explicitado como epígrafe, como los otros que iremos señalando. Cuando los agermanados expulsan a Diego Hurtado de Mendoza, I conde de Mélito (1468? - 1536), que había sido nombrado virrey en 1520, don Rodrigo de Mendoza, el marqués del Cenete, su hermano, acepta el cargo de Justicia de Valencia. Molina expone la situación crítica en la que estaba sumida la ciudad de Valencia con tanto dramatismo que se justifica la petición de ayuda, llegando

48. Consideramos que ciertos rasgos de mimetismo con la oralidad, o de diálogos dramáticos, como cuando se recogen las palabras pronunciadas por Mendoza en Morviedro o en Játiva, serían elementos de los que se sirve el autor para llenar de dramatismo las escenas bélicas y caracterizar más patéticamente a Mendoza.

49. La portada está descrita, junto con otros detalles tipográficos, en la base de datos sobre imprenta valenciana, Tipobibliografía valenciana, dirigida por Canet (2018). 
a afirmar que si el marqués no hubiese aceptado el bastón, Valencia habría sido «desolada» esa misma noche (f. 2, 1. 40-41):

Las iglesias monesterios y todas las otras personas que huyr no podían ni eran del colegio de los malvados cada hora morían [...]. La necessidad en fin era tanta que todos los estamentos y condición de gente con pública y universal embaxada se juntaron y fueron al real donde vuestra señoría estaba y con lágrimas de todos os suplicaron bolviéssedes vuestros ojos sobrellos: sobre los templos y cosas sagradas que en aquella desamparada ciudad estaban. (f. 2, 1.32-38)

En cambio, comenta, en señal de alegría y debido al agradecimiento que sentía el pueblo por la llegada del nuevo Justicia, las campanas de las iglesias entonaron el «Te deum laudeamus» (f. 3, 1. 1). Tras toda la anterior labor caótica de «destroçar, romper y alançar» (f. 3, 1. 7), se consiguió gracias a la asunción del cargo un esperanzador reposo. Y esa situación, después de Valencia, se contagiaría a otros lugares de España.

[2] «La bandera cobrada en Monviedro y la muerte de la muy illustre señora Marquesa» relata cómo en Sagunto consiguió Mendoza recuperar la bandera de la ciudad. Pero los sufrimientos de la guerra condujeron a la marquesa a la muerte: «viendo a vuestra señoría entre tanta multitud de armas y gente furiosa, que deste sobresalto y estraña turvacion breuemente perdió la vida» (f. 3, 1. 26-27). La muerte de la marquesa, que tuvo lugar en esos días, es descrita de forma somera y sobria, a diferencia de los episodios bélicos que están descritos con mayor detallismo y patetismo. Es probable que Molina no llegara a conocer a la marquesa, María de Fonseca (c. 1486-1521), segunda mujer del marqués, porque de haberlo hecho, se habría detenido tal vez con alguna mayor atención en la loa. Rodrigo Díaz había logrado contraer matrimonio con ella, venciendo toda clase de dificultades y oposiciones, incluidas las de la propia reina Isabel, forjando una de las historias románticas nobiliarias más destacadas de las primeras décadas del siglo (Boase, 2016: 39-42).

[3] «El artillería tomada camino de Monviedro» describe cómo el cabecilla «Viçent Pérez» (Vicent Peris) tenía de su lado un gran número de gente que quería «robar, alborotar, rebolver y saquear» (f. 3, 1.38). Al no poder establecerse en Valencia, debido a la defensa realizada por Mendoza, se marcharon hacia Monviedro $[s i c](\text { f. } 4,1.9)^{50}$. La estrategia que pretendían seguir para hacerse con la plaza era atacar al virrey en $\mathrm{Nules}^{51}$, donde se encontraba con pocas huestes, yluego aliarse con partidarios de otras regiones de Cataluña y Aragón (f. 4, 1. 16-20). Mendoza decide perseguir a los malvados, aunque esto supusiera poner en riesgo su vida (f. 4, 1.20-26), arengando a los suyos que empezaban a temer los riesgos del enfrentamiento, al ver tantos muertos y heridos (f. 4, 1. 26-38 $)^{52}$. Mendoza demuestra ser no solo un gran estratega, sino también un buen líder. Y es, además, magnánimo, puesto que una vez rendidos los enemigos — solamente por el miedo que generaba-, decide no darles muerte (f. 4, 1.38-43).

Molina compara la victoria de Mendoza con algunas de las de Hércules, en sus doce trabajos, diciendo que sus acciones han sido más arriesgadas que las del héroe mítico contra el león, la

50. «Monviedro» es flagrante error, por Murviedro. La onomástica de Monviedro corresponde a la iglesia de Nuestra Señora de Monviedro, en Salvatierra de Tormes (Salamanca).

51. Molina utiliza el término visorrey derivado de visrey, término usado en la Corona de Aragón en el siglo XV, que por influencia del catalán pasó al castellano como visorrey (DRAE).

52. La arenga la recoge Molina y vemos el carácter de oralidad y dramatismo del que hablábamos previamente cuando recoge las palabras de Mendoza: «biva el rey y mueran traydores» (f. 3, 1. 35-36). 
«sierpe» y el ladrón (Caco) (f. 5, 1. 4-8) ${ }^{53}$. Así pues, en la comparación entre el héroe clásico y Mendoza, resulta este segundo claramente victorioso: si Hércules se enfrentó a un león, Mendoza a una gran lombarda; si el primero hizo frente a la serpiente («culebra»), el segundo a la «culebrina» (pequeña lombarda); y, finalmente, Mendoza luchó contra miles de ladrones, mientras que Hércules contra uno solo (Caco ${ }^{54}$. En conclusión, de las hazañas de Mendoza «sin comparacion se siguió mayor beneficio y nació mayor bien que de todos aquellos doze [trabajos]» (f. 5, $1.7-8)^{55}$.

[4] El capítulo de «La entrada del S. Marqués en Xátiva» introduce nuevos episodios. Para Molina, la estrategia de los sublevados consistía en conquistar Játiva (Xàtiva), luego Valencia, y posteriormente extender su revuelta por el resto de España (f. 5, 1. 16-22). Compara ahora a sus enemigos con los godos, con los «moros» y con la traidora invasión que realizó el conde don Julián (f. 5, 1. 21-23). Vuelve a indicar que el pueblo de Valencia, ante la destrucción inminente, pide ayuda a Mendoza, del que insiste en destacar su piedad y buen hacer (f. 5, 1. 38-43). Al llegar a Játiva, Mendoza ve que el peligro era mayor del que se presuponía desde Valencia, porque mucha gente del campo - reconoce- se había aliado con los alborotadores (f. 6, 1. 1-7). De nuevo Molina cuenta con gran patetismo el enfrentamiento, con detalles como «no avíe ya ninguna esperança de la vida de los buenos que allí eran» (f. 6, 1. 12-13) $)^{56}$, y con descripciones de Játiva como una selva llena «de sierpes encantadas, en aquella tenebrosa Babilonia donde todos eran pies y donde todos cabeças, todos uno y uno todos, sin punto de orden seso ni concierto (f. 6, 1 . 22-24). En esta situación, una vez más, Mendoza se muestra como un gran caudillo a quien todos siguen, y es comparado ahora con Jonás, con Quinto Curcio y con Trajano Decio (f. 6, 1. 16-17). Haciendo uso del tópico literario de lo inefable, reconoce Molina no tener palabras suficientes para loar el valor de Mendoza (f. 6, 1. 24-25) ${ }^{57}$.

En el siguiente capítulo, [5] «La batalla avida dentro en Xátiva y prission del señor Marqués», indica que los hombres del marqués estaban constantemente en alerta ante un posible ataque

53. Molina recogería aquí distintas tradiciones. Por un lado, hace referencia a dos de los trabajos más conocidos: el enfrentamiento con el león de Nemea y con la serpiente Hidra. Sin embargo, también se hace eco de una tradición secundaria: la que el héroe griego robado por el ladrón Caco tras haber hurtado el ganado de Gerión. Podría interpretarse esta referencia con una doble intencionalidad ya que el gigante Gerión vivía en Eritnea, la actual Cádiz, mientras que el resto de seres mencionados por Molina habitaban regiones lejanas como Nemea y el lago de Lerna. Las serpientes, por su parte, pueden hacer referencia a las que envió Hera a Hércules para darle muerte de niño, contra las cuales también resultó victorioso Hércules; o, incluso, a la transformación de Aqueloo. Molina indica «sierpe», que es «una culebra de gran tamaño», lo que facilita un curioso paralelismo entre culebrina (arma artillera) y culebra.

54. La culebrina y la lombarda son dos armas de artillería. La primera, «antigua pieza de artillería, larga y de poco calibre» (DRAE) y la lombarda puede hacer referencia al «cañón antiguo de gran calibre»o al proyectil lanzado por este.

55. Es importante la alusión comparativa constante a Hércules, porque se trata de un personaje mitológico que el marqués tuvo siempre presente. Tal vez incluso los doce capítulos en los que se dividen las «hazañas de Rodrigo de Mendoza se pudieran vincular con los doce trabajos de Hércules. El patio interior renacentista del castillo de La Calahorra, mandado construir por Rodrigo de Mendoza, ya lucía todo un programa iconográfíco italianizante, presidido por magníficas esculturas de César y Hércules en reposo, en las columnas del arco de entrada, más una serie de medallas de emperadores. Véanse los trabajos sobre Hércules en el Renacimiento de Corzo Sánchez (en especial, 2012, donde relaciona este Hércules con los encargos de Rodrigo de Mendoza).

56. Incluye de nuevo muestras de oralidad cuando indica «algunas noches gritando començassen a apellidar 'paga, paga', y otros 'motín, motín’ (f. 6, 1.9-10). Además, un detalle que subraya el dramatismo del momento es cuando Molina indica que es el propio Lucifer quien mueve las bocas y los corazones de los que gritan.

57. No deja de ser sorprendente que Molina haga referencia a Quinto Curcio Rufo (s. I d. C), Trajano Decio (s. III d. C) y al profeta Jonás, como si de tres personajes coetáneos se tratara. Alude Molina a su deseo de que el valor de Mendoza sea comprendido por el lector de su obra: «confío yo que los buenos que lo leerán con su sentir alcançarán a donde mi desseo tira, y sentirán muy mas delo que digo, pues mi dezir y palabras quedan tan cortos» (f. 3, 1.26-28). 
traicionero («Judas empero no dormía») (f. 7, 1. 4). Luego, describe cómo gracias a la astucia de Mendoza pudo vencer el motín de enemigos que contra él se había alzado sin necesidad de una guerra cruenta (f. 7, 1. 19-32) y, aunque fue herido en el hombro, consiguió vencerles (f. 7, 1. 32$44)^{58}$. Sin embargo, es hecho prisionero, y se relata su cautiverio: «fuistes subido a la fotaleza y puesto en prisión como verdadero enemigo de los que lo eran del rey» (f. 8, 1. 3-4). Refiere Molina que durante diecinueve días estuvo preso y que esta situación fue tan peligrosa como las acaecidas en el campo de batalla (f. 8, 1.4) ${ }^{59}$. Por tanto, de nuevo elogia la serenidad y la falta de miedo de Mendoza, valores semejantes a los que mostró César cuando fue capturado por los piratas (f. $8,1.7-10)^{60}$. Mientras está preso Mendoza, Viçent Pérez aprovecha para atacar Algeciras, para poder acceder luego por mar a Valencia (f. 8, 1. 19-22). Entonces, los valencianos, poco después de la liberación de Mendoza, le suplican que acuda a proteger Valencia, ante la amenaza de Pérez (f. $8,1.23-28)$, y es cuando el marqués antepone el bienestar de las tierras del rey al de sus propias posesiones (f. 8, 1.28-34).

En el capítulo titulado [6] «El Jueves de Viçent Pérez» aparece la primera datación exacta de los acontecimientos: se trata del jueves, 27 de febrero del año 1522. Esta fecha fue efectivamente clave en tanto que marcó el comienzo de la derrota de los sublevados. Describe el enfrentamiento como desigual, ya que el marqués contaba con un grupo menos numeroso de tropas que Pérez, y aunque intentó Mendoza que el choque no resultara cruento, no fue posible (f. 9, 1.7-17). En [7] «La providencia hecha en los tres días siguientes por parte del illustre señor marqués contra Viçent Pérez», Molina cuenta la estrategia utilizada por Mendoza gracias a la cual consiguió la victoria en tan solo tres días. Apeló a todos los que trabajaban dentro de la ciudad (en la que aún permanecía Pérez) para concienciarles el grave peligro que corrían ellos y todo el reino si no le ayudaban en su empresa contra los alborotadores (f. 9, 1.25-42). Queda, de nuevo, demostrada la capacidad de oratoria y el poder de convicción de Mendoza.

En el capítulo [8], «La muerte de Viçent Pérez», se cuenta cómo se dio fin a la rebelión ${ }^{61}$. Entre el bullicio de gente, los gritos, los llantos y el terror, descritos por Molina, Mendoza aparece como salvador del pueblo valenciano ante la imposibilidad de la ayuda del monarca, que se encontraba en Flandes (f. 10, 1. 20-30). Si el enfrentamiento entre Mendoza y Pérez había sido comparado con el de Fabio y Aníbal en Italia (f. 10, 1.9), ahora se explicita que el riesgo que corrió Roma a manos de Espartaco, Catilina, Sila, Mario, Porsena, Breno y el mismo Aníbal, no fue comparable al que corrió Valencia (f. 10, 1. 31-32). Ni templos, ni iglesias, ni palacios, ni grutas podían proteger a los valencianos del peligro; solamente la casa de Mendoza sirvió de resguardo (f. 10, 1. 40-43). Contrapone esta actitud de las gentes a la valentía que demuestra Mendoza al en-

58. Molina recoge aquí las palabras de Julio César tras vencer a Pompeyo en la batalla de Munda (45 a. C.) (f. 7, 1. 44). Otra muestra de oralidad la encontramos cuando se indica lo que Mendoza les dijo a los amotinados: «Ea, pues, hijos: ¡Biva el rey! ¡Biva el rey!» (f. 7,1.23) y «a que fuerça es menester. Y tomastes una lança y diziendo “;Biva el rey!, ¡Mueran traydores!” (f. 7, 1. 30-31).

59. La datación no queda muy clara porque indica doce en un momento (1.4) y diecinueve unas líneas después (1. 12).

60. Concretamente Molina dice: «Ya sea verdad que el ánimo excelente de vuestra señoría, ageno de toda sombra de temor estando allí, no se mostró diferente en nada del que tuvo el mismo César [cuando se] vio preso en poder delos Pyratas» (f. 8, 1. 7-10).

61. Vuelve a ser interesante la puntualización cronológica que hace Molina («III de Marzo del sobredicho año XXII»), en tanto que recoge la tradición historiográfica clásica de indicar de forma exacta la datación de los episodios bélicos, como César o Salustio (f. 10, 1. 10-11). Molina llega incluso a especificar la hora, entre las cuatro o las cinco de la tarde, en que se produce la resolución final del conflicto (f. 11,1.25). 
frentarse al peligro, como era propio de sus antepasados (f. 11, 1.2-10 ${ }^{62}$. El enfrentamiento vuelve a ser descrito como desequilibrado en tanto que los seguidores de Mendoza eran menos (f. 12, 1 . 9-10). Por si fuera poco este detalle dramático, indica Molina que «no avía passo desde vuestra señoria a Viçent Perez que no fuesse el de la muerte» (f. 12, 1. 18) ${ }^{63}$. Al encontrarse ambos líderes, cuenta Molina que tanto terror sintió Pérez que desfalleció y tanto él como muchos de los suyos corrieron a esconderse o huyeron (f. 12, 1. 29-43). También apunta que uno de los seguidores de Pérez, con ayuda de Lucifer, consiguió herir al marqués, por lo que rápidamente corrió la voz de que había muerto (f. 13, 1. 2-14). Y es aquí donde Molina señala el motivo por el que escoge la obra de Apiano, por la similitud entre las guerras que el autor alejandrino narró y el gran valor mostrado por el marqués en las Germanías: «Triunpho por cierto que a solas es más glorioso que todos los quatro que Appiano nos recontara, redencion muy manifiesta, no solo deste Reyno mas de toda España, cuya seguridad mientra este fuego ardía estava asaz peligrosa y en condición» (f. 13, 1. 19-22).

En el capítulo [9] «La muerte del Encubierto», refiere Molina la muerte de Enrique Manrique, otro de los cabecillas de los agermanados, como una hazaña más de Mendoza. Aquel, después de la muerte de Pérez, se había alzado de nuevo contra el rey e intentó aliarse con algunas gentes de Aragón y Cataluña partidarias de la rebelión ${ }^{64}$. Nunca el reino había estado en tanto peligro como en aquellos momentos, como podrían perfectamente ratificar una serie de testigos de los acontecimientos que menciona (f. 14, 1.3-8). [10] «La venida de los de Algezira sobre Valencia» cuenta cómo solamente siete días más tarde de la muerte de Encubierto, es decir, el día 26 de mayo, se produce este ataque, del que se ofrecen pocos detalles, quitando el hecho de que fue acallado por Mendoza (f. 14, 1. 30-33). Se menciona, a continuación, [11] «La yda del señor Marqués en Castilla» $y$, consciente de haberlo contado de forma somera, se recomienda que quien quiera recabar más información sobre este episodio, fácilmente la podrá encontrar (f. 15, 1 . 4-6). Con la intención de elogiar de nuevo a Mendoza, relata, en el siguiente epígrafe, [12] «El continuo trato que los rebeldes siempre tovieron dentro en Valencia y en el reyno por matar al señor Marqués», que en Valencia un grupo de rebeldes se confabularon y acordaron dar muerte al marqués; sin embargo, y aunque lo intentaron en diversas ocasiones, nunca pudieron conseguirlo.

En el [13] «Epílogo de lo suso dicho y conclusión de la presente Epístola», recoge de nuevo Molina la idea de que los elogios antes realizados no son exageraciones, sino que responden a la caracterización fidedigna de la figura de Mendoza ${ }^{65}$. Asimismo, incluye Juan de Molina una larga enumeración con algunos de los efectos de la bonanza de la que pueden disfrutar los valencianos en su tiempo, gracias a la labor de Mendoza. Por citar algunos: los mercaderes compran y venden sin temor, y las reliquias y el oro siguen estando en las iglesias. De hecho, indica que: «si possee-

62. Hace referencia a la genealogía de los Mendoza, que siempre había conseguido sus tierras en guerras y ayudando a la realeza en épocas de crisis, como la vivida por el marqués (f. 11,1.5-10). El elogio a la labor liberadora de Mendoza lleva a Molina a comparar a Pérez, en contraposición, con un faraón que tiene como cautivos a los pueblos de Dios (f. 11,1. 14-15).

63. También encontramos una muestra de mímesis oral, característica de las narraciones bélicas que hace Molina, cuando dice Mendoza: «iBiva el rey, mueran traydores!» (f. 12,1.22).

64. Por este motivo, Molina compara la suya con la revuelta organizada por Gayo Amatio en tiempos de Marco Antonio (f. 13, 1. 29). Demuestra aquí Molina que solo menciona los pasajes que considera de menor relevancia, como el degollamiento del Encubierto. Vuelve a ser, en cambio, muy exacto en la datación, ya que indica que ocurrió el día diecinueve de mayo del mismo año XXII.

65. Insiste Molina en que se siente aliviado contra posibles reproches de imparcialidad, sabiendo que quienes lo lean dirán que lo dicho es cierto: «Consuelo es para mí que esté escrito, que leyendo esto o doquier que se leyere a una boz dirán: "Por cierto, assí es verdad, y muy más pudiera escrevir” $\gg($ f. 16, 1. 40-43). 
mos las vidas e haziendas que tenemos del menor al mayor (después de Dios) a vuestra señoría lo deven y devemos» (f. 16, 1. 20- 22). Recurrente se vuelve la idea de acreditar la veracidad al final del elogio. Y, así, señala Molina que tan verdad es lo que ha contado como que los hechos de grandes emperadores y generales romanos, como Furio Camilo, Horacio Cocles o Julio César, no mostraron tanto valor como el demostrado por Mendoza (f. 17, 1. 1-7) ${ }^{66}$.

El texto recoge, para ir concluyendo, en tinta roja y en mayúsculas, enfatizándolas, las palabras del lema, divisa o motto de Mendoza: «LAUDO MIA SORTE» (f. 17, 1. 8), haciendo paradójico y llamativo que elogie su suerte un personaje cuya vida ha pasado tantas vicisitudes ${ }^{67}$ :

\section{Joelta ciudadba moltrado. LA VDO MIA SORTE ació pues:con tāta razon pi}

Fig. 6

Y añade a la mención del motto que todos los habitantes de Valencia loan (y loarán) esa suerte, porque gracias a ella, han podido preservar la suya (f. 17, 1. 11-14). Asimismo, indica el cronista que la loa que acaba de realizar tiene la función de dotar de inmortalidad las hazañas antes narradas porque, aunque otros contemporáneos suyos no sepan dar suficiente importancia al valor de estas acciones, al menos quedará la «Epístola» como constancia imborrable de su mérito. Reconoce aquí Molina la capacidad de la escritura histórica, como nuntia vetustatis (como la definía Cicerón), de hacer que los hombres sean recordados siempre. En definitiva, para Juan de Molina los triunfos de Mendoza son parangonables a los que Apiano cuenta de las guerras civiles de Roma. Termina pidiendo perdón al marqués por atreverse a recoger en una sola obra su «Epístola» y la narración de las guerras contadas por Apiano, y se disculpa por su estilo rudo. Asimismo, después de desearle una longeva vida al marqués, firma la «Epístola», indicando el lugar y día en que fue escrita: Valencia, 20 de agosto de 1522. Es entonces cuando comienza propiamente la obra (la traducción de Apiano), explicando con una anticipatio el argumento de la misma.

\section{Conclusiones}

La edición de la traducción del texto de Juan de Molina, publicada por Juan Jofre en 1522 no se puede entender solamente como una traducción literal de cuatro de los libros de las guerras exteriores de la Historia Romana de Apiano Alejandrino. Incluye muchos elementos más, que presuponen una serie de complejos contextos, que van desde los socio-históricos, políticos, ideológicos, cortesanos, de mecenazgo o de relaciones personales, de relaciones con la nobleza y con otros intelectuales de la época, hasta las vinculadas con el mundo de la imprenta y la producción del libro. Que un autor decida traducir una obra historiográfica clásica a su lengua vulgar en pleno

66. Las únicas referencias más explicitas son a la hazaña de Furio Camilo y a la de Horacio Cocles. Del primero indica que recuperó las banderas de la ciudad de Roma y del segundo que defendió de Porsena el puente, sin mencionar cuál (fue el del río Tíber). Son ambiguas las referencias a Junio Bruto y a Julio Cesar, quizás por considerar que eran más conocidos que los anteriores. Incluye de nuevo Molina a personajes alejados cronológicamente entre sí.

67. El motto es estudiado por Boase (2016), en su contexto, junto con otros de la familia y del propio marqués. Boase aporta una serie de poemas, en el Cancionero General y en El cortesano de Lluís de Milà, que hacen juegos de palabras con el lema. 
siglo XVI, recurriendo a la versión latina, nos sitúa ante la importancia de la tarea divulgativa de Molina, un «letraherido» intelectual activo en la época del virreinato de Valencia, entre los años 1520 y 1550 . Molina critica las obras de caballerías, recurriendo al criterio de su falta de veracidad histórica, pero participa él mismo en la producción de algunos de los libros que difunde la misma imprenta valenciana en esos años (Arderique, Lepolemo).

El parangón que establece Juan de Molina entre las guerras civiles acaecidas recientemente en Valencia y la realidad pasada en la Antigüedad es fundamental a la hora de entender el proemio y la traducción, así como la imbricación recíproca de ambos. Hay una constante vinculación diacrónica entre la confusión política romana descrita por Apiano y la situación de inestabilidad social y caos moral de la contemporaneidad, centrados en la revuelta de las Germanías, que según ambos autores solo puede resolver una monarquía dura, que delegue en hombres capaces su papel represor. Reseñable es también la forma en la que Molina introduce las referencias a la realidad grecolatina cuando evidencia las similitudes entre Mendoza y personajes tan ilustres como Julio César; además, es capaz de abrir conexiones varias entre la realidad más reciente (la suya, vivida por Mendoza) y personajes mitológicos (Hércules), bíblicos (como Jonás), del siglo V- IV a.C. (como el patricio Furio Camilo), o de la realidad histórica española (como el Cid). Dando así una dimensión de atemporalidad y una plataforma de excepcionalidad a la biografía del marqués del Cenete.

\section{Bibliografía}

Alvar, Carlos (2010), Traducciones y traductores: materiales para una historia de la traducción en Castilla durante la Edad Media, Alcalá de Henares, Centro de Estudios Cervantinos.

Apianus Alexandrinus (1500), De bellis ciuilibus Romanorum [P. Candidi... in latinum traductis], Venecia, Christoferum de Pensis. http://bivaldi.gva.es/es/consulta/registro. cmd?id=2709

Arronis Llopis, Carme (2013), «Juan de Molina, autor - y no traductor- del Vergel de Nuestra Señora», Studia Aurea, 7, pp. 389-416.

Beltrán, Rafael (1997), «La justificación de la escritura en las biografías de Alonso de Carrillo y Alonso de Monroy», en Actas del vi Congreso Internacional de la Asociación Hispánica de Literatura Medieval (Alcalá de Henares, 1995), ed. J. M. Lucía Megías, Alcalá de Henares, Univ. de Alcalá, vol. I, pp. 265-77.

(2019a), «"Humos escuros y espesas nieblas" en los primeros ataques a los libros de caballerías: Tirante el Blanco (1511) frente a las críticas de Juan de Molina, Luis Vives y Jerónimo Sempere $\gg$, Historias fingidas, 7, pp. 61-127.

(2019b), «Magia y milagros de San Paulicio en Arderique (1517): el cadáver del santo, la pareja infecunda y el nacimiento heroico», Revista de Literatura, vol. LxxxI, núm. 162, pp. 365-393.

Berger, Philippe (1987), Libro y lectura en la Valencia del Renacimiento, Valencia, Alfons el Magnànim, 2 vols.

(1990), «À propos des romans de chevalerie à Valence», Bulletin Hispanique. 92, pp. 83-99.

(2004), «Del manuscrito a la imprenta: inercia y sinergia», Bulletin Hispanique. 106, pp. 143-159.

BoAse, Roger (2016), «María de Fonseca (c.1486-1521) and the Marquis of Zenete (14731523): Aristocratic Rebels and Patrons of Renaissance Culture », Magnificat, 3, pp, 37-66. 
Bognolo, Anna (2002), «El Lepolemo, Caballero de la Cruz y el Leandro el Bel», Edad de Oro, 21, pp. 271-288.

Botella Ordinas, Eva (2000), «Redención de la virtud. La primera traducción castellana del Arte della Guerra de Maquiavelo», Espacio, tiempo y forma. Serie IV, Historia Moderna, 13, pp. 183-219.

Bravo García, Antonio (1975), «Apiano en España: notas críticas», Cuadernos bibliográficos, 32, pp. 29-39.

(1977), «Sobre las traducciones de Plutarco y de Quinto Curcio Rufo hechas por Pier Candido Decembrio y su fortuna en España», Cuadernos de Filología Clásica, 12, pp. 143-185.

Bucher, Gregory (2000), «The Origins, Program, and Composition of Appian's Roman History», Transactions of the American Philological Association, 130, pp. 411-458.

CANET, José Luis (1999), «El impresor valenciano Juan Jofré», en Nicasio Salvador Miguel (ed.), Tragicomedia de Calisto y Melibea (Valencia, Juan Joffre, 1514), Valencia, Institució Alfons el Magnànim-Biblioteca Nacional, pp. 39-52.

(2018), Tipobibliografía valenciana siglos XV y XVI [Base de datos].

http://parnaseo.uv.es/tipobibliografia/Tipobibliografia.html

Carpenter, Dorothy Molloy (1999), Arderique (Valencia, Juan Viñao, 1517). Guía de lectura, Alcalá de Henares, Centro de Estudios Cervantinos.

(ed.) (2000), Arderique, 'Los libros de Rocinante', 7, Alcalá de Henares, Centro de Estudios Cervantinos.

Castaño Santos, Soledad (2018), «"La farsa del Canonge Ester” en El cortesano de Luis Milán: espectacularidad teatral en la corte de los duques de Calabria», Lemir, 22, pp. 421-448.

Coroleu Lletget, Alejandro (2004), «Entre història i ficció: per a un estudi de la fortuna d'Apià al Renaixement», Estudi general: Revista de la Facultat de Lletres de la Universitat de Girona, 23-24, pp. 283-294.

Corzo SÁnchez, Jorge Ramón (2012), «Iconografía de los “triunfos” de Hércules en los frisos de Vélez Blanco», Laboratorio de Arte: Revista del Departamento de Historia del Arte, 24, pp. 113-136.

De Marinis, Tammaro (1947-1952), La biblioteca napoletana dei re d'Aragona, Milán, 19471952, Milán, Hoepi, 4 vols; Supplemento, Verona, 1969, 2 vols.

Ferrer Del Río, Estefanía (2020), Rodrigo de Mendoza: noble y coleccionista del Renacimiento, Madrid, Sílex.

GabBA, Emilio (1959), «Storici greci dell'impero romano de Augusto ai Severi», Rivista Storica Italiana, 71, pp. 361-381.

(ed.) (1967), Appiani Bellorum civilium liber primus, 'Biblioteca di studi superiori', 37, Florencia, La Nuova Italia.

Garcia CÀrCel, Ricardo (1975), Las Germanías de Valencia, Barcelona. Península.

- (1981), La revolta de les Germanies, València, Institució Alfons el Magnànim.

Gómez Espelosín, Francisco Javier (2009), «Contradicciones y conflictos de identidad en Apiano», Gerión, 27, pp. 231-250.

(ed.) (2016), Apiano, Guerras Ibéricas, Madrid, Alianza.

Gómez Moreno, Ángel (1994), España y la Italia de los humanistas: primeros ecos, Madrid, Gredos. 
González Rolán, Tomás, Antonio Moreno Hernández y Pilar Saquero Suárez-SomonTE (2000), Humanismo y Teoría de la Traducción en España e Italia en la primera mitad del siglo $X V$ (Edición y estudio de la «Controversia Alphonsiana»), Madrid, Ediciones Clásicas.

Gutiérrez del CaÑo, Marcelino (1913-1914), Catálogo de manuscritos existentes en la Biblioteca Universitaria de Valencia, Valencia, Librería Maraguat, 3 vols.

Kristeller, Paul Oskar (1966), «Pier Candido Decembrio and his unpublished treatise on the Immortality of the Soul», en L. Wallach (ed.), The classical Tradition. Literary and historical studies in honor of $\mathrm{H}$. Caplan, Ithaca, Nueva York, Cornell, U. P., pp. 536-558.

López Estrada, Francisco (1952), «Una edición desconocida del Enquiridion (Valencia, 1528, por Costilla)», Revista de Archivos, Bibliotecas y Museos, 58, pp. 449-463.

LuCE, James (1964), «Appian’s Egyptian History», Classical Philology, 59, pp. 259-262.

Lucía Megías, José Manuel (1992), «Pier Candido Decembrio y España: estado de la cuestión», en J. M. Lucía Megías, P. Gracia Alonso y C. Martín Daza (eds.), Actas del II Congreso Internacional de la Asociación Hispánica de Literatura Medieval, Alcalá de Henares, Universidad de Alcalá, vol. I, pp. 465-474.

Mahiques Climent (2019), «Sobre la Epístola proemial y las obras poéticas de Onofre Almudéver», Revista de Cancioneros impresos y manuscritos, 8, pp. 128-209.

Matterni, Marta (2012), «Pier Candido Decembrio: una 'biblioteca' ibérica de historia clásica», en Patrizia Botta (coord.), Rumbos del hispanismo en el umbral del Cincuentenario de la Asociación Internacional de Hispanistas, Roma, Bagatto Libri, pp. 35-41.

MiLÁN, Luis (2010), El cortesano, ed. Josep Vicent Escartí, Valencia, Institució Alfons el Magnànim.

MolinA, Juan de (1522), Los Triumphos de Apiano, Valencia, Juan Joffre. http://bivaldi.gva.es/ es/consulta/registro.cmd?id $=3170$

Moll, Ángela (1992), «Pier Cándido Decembrio y España: estado de la cuestión», en J. M. Lucía Megías P. Gracia Alonso y C. Martín Daza (eds.), Actas del iI Congreso Internacional de la Asociación Hispánica de Literatura Medieval, Alcalá de Henares, Universidad de Alcalá, vol. I, pp. 265-274.

Montaner, Alberto (ed.) (1997), Antonio Beccadelli, Libro de los dichos y hechos elegantes y graciosos del sabio Rey don Alonso de Aragón, según la traducción del bachiller Juan de Molina, ed. facsimilar, Zaragoza, Cortes de Aragón.

Morales Ortiz, Alicia (2000), Plutarco en España: traducciones de Moralia en el siglo XVI, Murcia, Universidad de Murcia.

Neri, Stefano (2006), Lepolemo (Valencia, Juan Jofré, 1521). Guía de lectura, Alcalá de Henares, Centro de Estudios Cervantinos.

Pérez Priego, Miguel Ángel (1981), «La obra del bachiller Juan de Molina, una práctica del traducir en el Renacimiento español», 1616: Anuario de la Sociedad Española de Literatura General y Comparada, 4, pp. 35-43.

Pérez Vilatela, Luciano (2000), «En torno a la errónea ubicación de Sagunto y sus orígenes en Apiano», Arse: Boletín anual del Centro Arqueológico Saguntino, 34, pp. 63-78.

Pflaum, Hans-Georg (1950), Les procurateurs équestres sous l'Empire romain, París, Librairie d'Amérique et d'Orient, Adrien Maisonneuve.

Romero Tovar, Leonardo (ed.) (1978), Alonso Maldonado, Vida e historia del maestre de Alcántara don Alonso de Monroy, Tarragona, Tarraco. 
Rovira Soler, José Carlos (1990), Humanistas y poetas en la corte napolitana de Alfonso el Magnánimo, Alicante, Instituto de Cultura Juan Gil Albert.

SANCho Royo, Antonio (ed.) (1980), Apiano, Historia Romana, Madrid, Gredos.

Steiner, George (1980), Después de Babel. Aspectos del lenguaje y la traducción, Adolfo Castañón (trad.), México-Madrid-Buenos Aires, Siglo XXI.

Valero Moreno, Juan Miguel (2017), «Palabras antiguas para un mundo nuevo: Pier Candido Decembrio, vocabulista en castellano», Quaderns d'Italià, 22, pp. 225-240. 